\title{
Fiber Optic Hydrogen Sensors: a Review
}

\author{
Minghong YANG* and Jixiang DAI \\ National Engineering Laboratory for Optical Fiber Sensing Technologies, Wuhan University of Technology, Wuhan, \\ 430070, China \\ *Corresponding author: Minghong YANGＥ-mail: minghong.yang@whut.edu.cn
}

\begin{abstract}
Hydrogen is one of the next generation energies in the future, which shows promising applications in aerospace and chemical industries. Hydrogen leakage monitoring is very dangerous and important because of its low ignition energy, high combustion efficiency, and smallest molecule. This paper reviews the state-of-art development of the fiber optic hydrogen sensing technology. The main developing trends of fiber optic hydrogen sensors are based on two kinds of hydrogen sensitive materials, i.e. palladium-alloy thin films and Pt-doped $\mathrm{WO}_{3}$ coatings. In this review work, the advantages and disadvantages of these two kinds of sensing technologies will be evaluated.
\end{abstract}

Keywords: Optical fiber sensors, hydrogen sensing, thin films, coatings

Citation: Minghong YANG and Jixiang DAI, “Fiber Optic Hydrogen Sensors: a Review," Photonic Sensors, 2014, 4(4): 300-324.

\section{Introduction}

Hydrogen is a promising candidate for the next generation energy due to its excellent characteristics such as cleanness, high efficiency, and renewability. Great research interest has been attracted in the fields of the hydrogen preparation, storage, and application. Hydrogen is also dangerous because of its low ignition energy, high combustion efficiency, and smallest molecule. Therefore, hydrogen leakage monitoring is very important in these fields. Currently, most of the commercially-available hydrogen sensors are based on electrochemical principles. Due to the possibility of generating electric sparks, these electrochemical hydrogen sensors could be combustion sources in the high hydrogen concentration. The optical fiber hydrogen sensor is very suitable for hydrogen leakage detection owing to its intrinsic safety and anti-electromagnetic interference. The optical fiber hydrogen sensor has attracted intensive research interest due to its potential for the next generation of the hydrogen sensor. At present, there are several kinds of optical fiber hydrogen sensors, such as the evanescent sensor [1-7], micro-mirror sensor [8-9], surface plasmon resonance (SPR) sensor [10], acoustic resonator sensor [11], and fiber Bragg grating (FBG) sensor [12-16]. Among these sensors, the FBG hydrogen sensor is more suitable for the distributed measurement due to its wavelength multipliable capability. Another advantage of the FBG is that it is easy for temperature compensation [16-19] which can reduce the influence of optical source's intensity so as to improve the sensor's accuracy. Therefore, it is very meaningful to utilize the FBG hydrogen sensor for hydrogen leakage detection.

Currently, the most sensitive FBG hydrogen sensor is based on $\mathrm{WO}_{3}$ doped with the Pt layer on which hydrogen can undergo an exothermic reaction [15]. The sensor has the fast response and high sensitivity, but it still has the potential to be

Received: 31 August 2014 / Revised version: 12 September 2014

(C) The Author(s) 2014. This article is published with open access at Springerlink.com

DOI: $10.1007 / \mathrm{s} 13320-014-0215-y$

Article type: Review 
explosive in higher hydrogen concentrations. FBG hydrogen sensors based on the pure Pd film have nature safety, however these sensors are easily suffered from Pd film's fatal fracture caused by its $\alpha-\beta$ phase transition $[6,20]$. Moreover, the pure Pd film has a poor adhesion towards the optic fiber, and it may peel off when it is exposed to hydrogen [14]. These defects can cause the hydrogen sensor's irreversible response, leading to the hysteretic effect during the hydrogen adsorption and desorption process. It has been demonstrated that the side-polished $\mathrm{FBG}$ coated with the $\mathrm{WO}_{3}-\mathrm{Pd}$ composite film shows the high sensitivity to hydrogen, but the hydrogen sensor still has the hysteretic effect [16] due to its lattice defects. Therefore, selecting the proper hydrogen sensitive film is very important for the hydrogen sensor.

\section{Fiber optic hydrogen sensors with $\mathrm{Pd} / \mathrm{Ag}$ composite films}

It has been reported that the $\mathrm{Pd}_{75} / \mathrm{Ag}_{25}$ composite film has certain plasticity to tense strength [21-23] during hydrogen response; therefore, it has been widely used in the hydrogen separating industry. To improve the sensor's repeatability, the $\mathrm{Pd} / \mathrm{Ag}$ composite film is chosen as the hydrogen sensitive film to overcome the hysteretic effect during the hydrogen absorption and desorption process. The $\mathrm{Cr}$ film is selected as the basal layer to improve the adhesion between the $\mathrm{Pd} / \mathrm{Ag}$ composite film and FBG. In order to improve the hydrogen sensor's sensitivity, the FBG is etched by the hydrofluoric acid (HF) solution to reduce its diameter. Generally, the etched FBG is very fragile, and it is not suitable for the practical application. However, the etched FBG still can be used for the application if it is properly protected. With the aim to prepare the hydrogen sensor with good performance, the etched FBG hydrogen sensors based on the $\mathrm{Pd} / \mathrm{Ag}$ composite film are proposed, and their sensing characteristics have been investigated.

As it is well known, the reflected wavelength $\left(\lambda_{B}\right)$ of the FBG has correlation with its effective refractive index $\left(n_{\text {eff }}\right)$ and grating pitch $(\Lambda)$. The equation can be expressed as [24]

$$
\lambda_{B}=2 n_{\text {eff }} \Lambda \text {. }
$$

The $\mathrm{Pd} / \mathrm{Ag}$ coating can expand when it absorbs hydrogen, which will induce strain in the underlying FBG. The grating pitch of the FBG will be changed by the volume expansion of the $\mathrm{Pd} / \mathrm{Ag}$ composite film, which can cause the wavelength shift of the FBG. Since the volume expansion induced by the formation of $\mathrm{PdH}_{x}$ [6] depends on the hydrogen concentration, the FBG wavelength shift has correlation with the hydrogen concentration. Therefore, the hydrogen concentration can be deduced by measuring the wavelength shift of the FBG

The polyimide coating around the signal mode fiber was removed by the fiber stripper before ultraviolet (UV) exposure. A Lambda Physik excimer laser (COMPex-150T) operating at $248 \mathrm{~nm}$ was used as the laser source to write the FBG in the single mode fiber by the phase mask method [25]. The FBGs used in our experiments were fabricated on a single mode $125-\mu \mathrm{m}$ fiber with the $9 \mu \mathrm{m}$ $10 \mu \mathrm{m}$ diameter core region. The length of the optical fiber exposed to UV light was about $8 \mathrm{~mm}$. The FBG with the central wavelength of $1302.685 \mathrm{~nm}$ was prepared by UV light through an 898.51-nm period phase mask. The refractive index modulation of the fiber core was about $4 \times 0^{-6}-6 \times 0^{-6}$, yielding to a reflectivity approaching $90 \%$ at the Bragg wavelength. After UV exposure, the FBG was fixed on the polyvinyl chloride polymer sheet for the etching process. Then, the single mode FBG fiber was dipped in the $50 \% \mathrm{HF}$ solution for tens of minutes to remove the cladding layer. In our experiment, FBGs with diameters of $38 \mu \mathrm{m}$ and $20.6 \mu \mathrm{m}$ were prepared by dipping in the HF solution for 37 minutes and 46 minutes, respectively. After the etching process, the etched FBG was baked by infrared light for the next process. 100-nm $\mathrm{Pd}_{76} / \mathrm{Ag}_{24}$ composite thin films were deposited on the etched FBG fiber by using a BESTECH sputtering system. 
To ensure the selectivity of the hydrogen sensitive film, the 10-nm-pure-Pd film was set as the protective layer outside the $\mathrm{Pd}_{76} / \mathrm{Ag}_{24}$ composite film. Before preparing the hydrogen sensitive film, the 10-nm Cr film was deposited on the side face of the FBG by the radio-frequency (RF) sputtering process. On the one hand, the $\mathrm{Cr}$ film can stop $\mathrm{H}_{2} \mathrm{O}$ penetrating into the optical fiber so that it can be used as the protective layer. On the other hand, the $\mathrm{Cr}$ film has the good adhesion toward the optical fiber; therefore, it can be employed as a basal layer to overcome the material mismatch of the $\mathrm{SiO}_{2}$ and $\mathrm{Pd} / \mathrm{Ag}$ composite film so as to improve the sensor's stability. Under the 0.5-Pa sputtering pressure of Ar, the deposition power for $\mathrm{Pd}$ and $\mathrm{Ag}$ targets were $100 \mathrm{~W}$ and $55 \mathrm{~W}$, respectively, which corresponded to the deposition rates of $0.14 \mathrm{~nm} / \mathrm{s}$ and $0.05 \mathrm{~nm} / \mathrm{s}$, respectively. With this sputtering process, the atomic ratio of $\mathrm{Pd}$ and $\mathrm{Ag}$ was about 76:24. During the sputtering process, the thickness of the hydrogen sensitive was monitored by the quartz crystal method. Meanwhile, coatings on several $10 \mathrm{~mm} \times$ $10 \mathrm{~mm}$ Si pieces were also prepared in the same run for the further characterization. After the sputtering process, the etched FBG coated with the $\mathrm{Pd} / \mathrm{Ag}$ composite film was sealed in the porous stainless steel tube for hydrogen test.

Figure 1 shows the schematic diagram of the fiber-hydrogen sensor characterization system. The hydrogen sensing performance was measured at the room temperature of $15.4{ }^{\circ} \mathrm{C}$ using air as the carrier gas. The relative humidity of the atmosphere was about $61.7 \%$. During hydrogen concentration characterization, the reflected wavelength was collected with a BCD-100 FBG demodulator. The BCD-100 FBG demodulator was equipped with a fiber fabry-perot tunable filter (FFP-TF) from Micron Optics Inc., USA, which can provide high precision $(1 \mathrm{pm})$ to detect a slight wavelength shift of the FBG. The varying hydrogen concentrations were provided by changing the flowing rate of $\mathrm{H}_{2}$. A commercially available MIC-500 hydrogen concentration meter based on the chemical electrics principle was connected to the gas room for calibration. A standard non-coated FBG with the similar wavelength was used as the temperature compensating element. The measured data were recorded by a computer connecting with the FBG demodulator for the further data treatment.

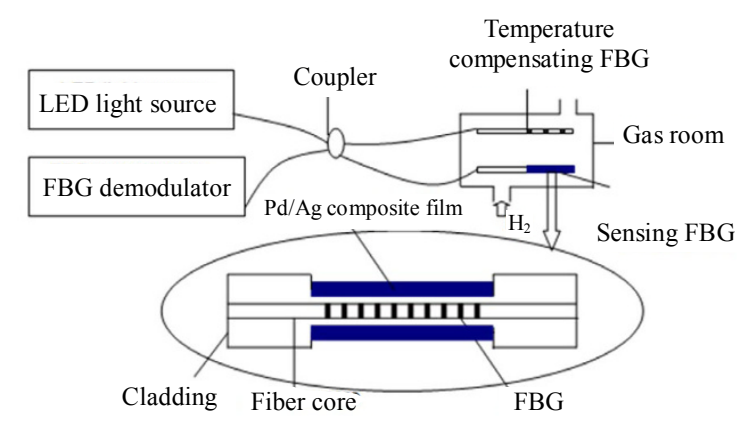

Fig. 1 Configuration of the optical fiber hydrogen sensor characterization.

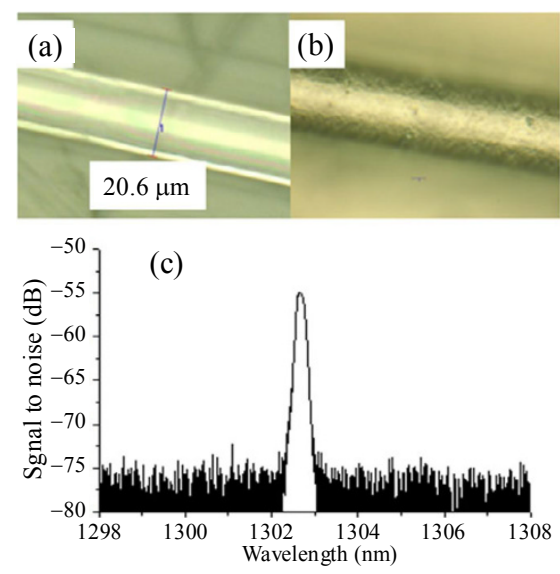

Fig. 2 Microphotography of the chemically-etched FBG-20.6 $\mu \mathrm{m}$ (a) before and (b) after sputtered with 110-nm $\mathrm{Pd} / \mathrm{Ag}$ composite films, and (c) reflective spectrum of the etched FBG-20.6 $\mu$ m sputtered with 110-nm Pd/Ag composite films.

Figure 2(a) shows the etched FBG enlarged by 1000 times in length. Obtained by a VHX-100 digital microscope, the diameter of the etched FBG was about $20.6 \mu \mathrm{m}$. Figure2(b) is the morphology of the etched FBG sputtered with the 110-nm $\mathrm{Pd} / \mathrm{Ag}$ composite film. After deposited with the $\mathrm{Pd} / \mathrm{Ag}$ composite film, the etched FBG looked not as transparent as before. The reflective spectrum of the etched FBG coated with the $\mathrm{Pd} / \mathrm{Ag}$ composite films was measured by an optical spectrum analyzer (AQ6370B, YOKOGAWA). As shown in Fig. 2(c), the etched FBG still has a good reflective spectrum 
after the etching and sputtering processes, which can provide the reliable optical signal for hydrogen test. The advantage of the FBG hydrogen sensor is its wavelength multipliable capability, which can reduce the influence of optical source's intensity so as to improve the sensor's accuracy.

The elemental analysis of the $\mathrm{Pd} / \mathrm{Ag}$ composite film deposited on the Si piece was carried out by energy dispersive X-ray analysis (EDAX) using an X-ray detector attached to the field emission scanning electron microscope (FE-SEM S-4800, Hitachi, Japan). The EDAX result showed the atom ratio of $\mathrm{Pd}: \mathrm{Ag}$ was about 78:22, which was consistent with the actual Pd:Ag of the $100-\mathrm{nm}$ $\mathrm{Pd}_{76} / \mathrm{Ag}_{24}$ composite film and 10-nm-pure-Pd film. The X-ray diffraction pattern of the $\mathrm{Pd} / \mathrm{Ag}$ composite film was obtained on a X-ray diffractometer (XRD D8 Advance, Brucker, German) using a $\mathrm{Cu} \mathrm{K} \alpha$ radiation source operating at $40 \mathrm{kV}$ and $30 \mathrm{~mA}$. The relatively weak peak at $2 \theta=29^{\circ}$ was the characteristic peak of monocrystalline silicon. As shown in Fig. 3, the $\mathrm{Pd} / \mathrm{Ag}$ peaks could be found at $2 \theta=40^{\circ}, 46.7^{\circ}, 68.2^{\circ}, 82.4^{\circ}$, and $86.6^{\circ}$ corresponding to the cubic phase (lll $\left.\begin{array}{lll}1 & 1 & 1\end{array}\right),\left(\begin{array}{lll}2 & 0 & 0\end{array}\right)$,

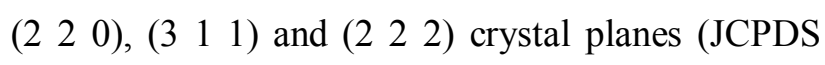
65-6174). The XRD result demonstrates the atoms in the $\mathrm{Pd} / \mathrm{Ag}$ composite film are in the orderly arrangement.

Figure 4 displays the microphotography of $\mathrm{Si}$ pieces coated with the 110-nm-Pd/Ag-composite film [Fig. 4(a)] before and [Fig.4(b)] after exposing to hydrogen. The white particles are Ag atoms, but Ag particles look much less than Pd particles due to the 10-nm-pure $\mathrm{Pd}$ film on the surface of the $\mathrm{Pd}_{76} / \mathrm{Ag}_{24}$ composite film. It can be seen that the $\mathrm{Pd} / \mathrm{Ag}$ composite film looks uniform and dense. Moreover, there is no crack on the surface of the hydrogen sensitive film. These results demonstrate that the $\mathrm{Pd} / \mathrm{Ag}$ composite film has the good mechanical performance during the hydrogen response.

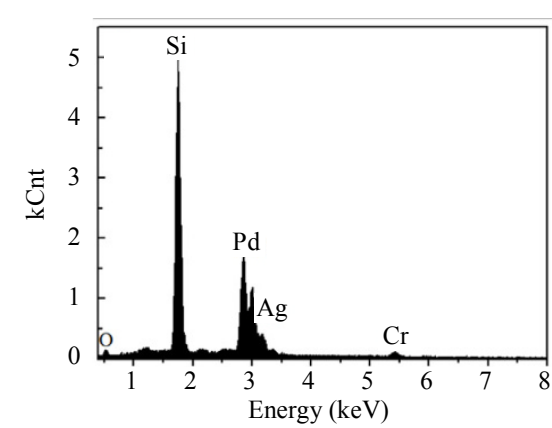

(a)

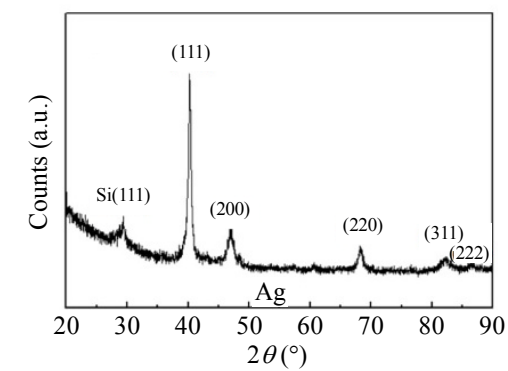

(b)

Fig. 3 Micro-structure and composition characterization: (a) EDAX pattern and (b) X-ray diffraction of the 110-nm $\mathrm{Pd} / \mathrm{Ag}$ composite film.
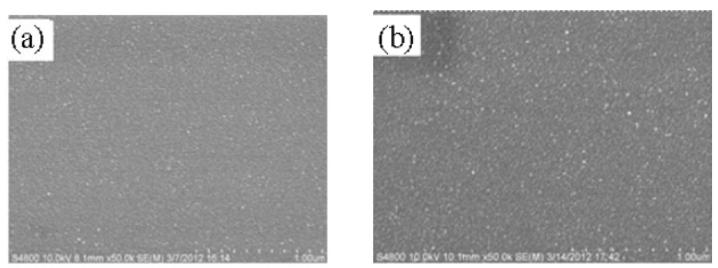

Fig. 4 SEM images of the 110-nm $\mathrm{Pd} / \mathrm{Ag}$ composite film (a) before and (b) after hydrogen response.

Figures 5(a), 5(b), and 5(c) illustrate the repeatabilities of the FBG- $125 \mu \mathrm{m}, \mathrm{FBG}-38 \mu \mathrm{m}$ and FBG-20.6 $\mu \mathrm{m}$ coated with the 110-nm $\mathrm{Pd} / \mathrm{Ag}$ composite film in the three hydrogen response cycles. The relative wavelength is derived by subtracting the central wavelength of the reference FBG from that of the sensing FBG. During the three-cycle's response, the sensor has the good repeatability to the $4 \%$ hydrogen concentration. There is little hysteretic effect during the hydrogen response due to the good mechanical strength of the $\mathrm{Pd} / \mathrm{Ag}$ composite film, which is corresponding with the good appearance of the hydrogen sensitive film as shown in Fig. 4. Compared to the amorphous $\mathrm{WO}_{3}-\mathrm{Pd}$ composite film [16], the cubic phase $\mathrm{Pd} / \mathrm{Ag}$ composite film has less sensitivity but better repeatability. Ag is not sensitive to hydrogen, so the 
$\alpha-\beta$ phase transition of the $\mathrm{Pd} / \mathrm{Ag}$ composite film can be suppressed by alloying with Ag [21]. Therefore,

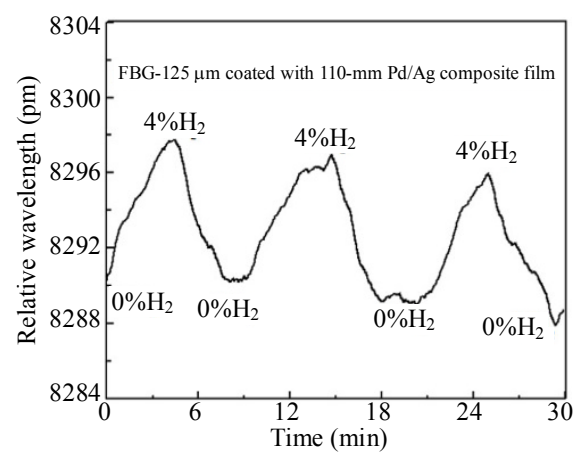

(a)

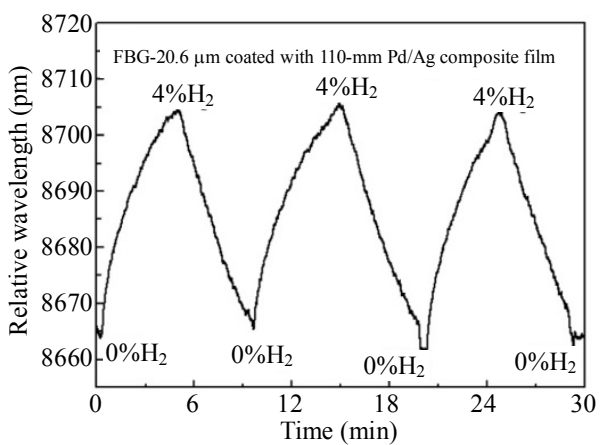

(c) the FBG hydrogen sensor's reversibility can be improved by using the $\mathrm{Pd} / \mathrm{Ag}$ composite film.

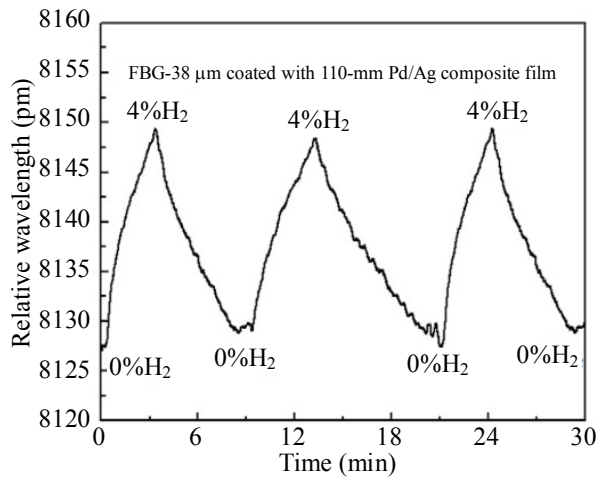

(b)

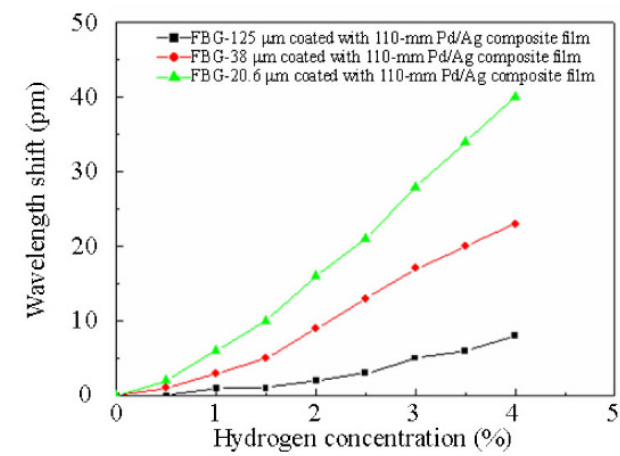

(d)

Fig. 5 Three cycles of the hydrogen response of (a) FBG-125 $\mu \mathrm{m}$, (b) FBG-38 $\mu \mathrm{m}$, and (c) FBG-20.6 $\mu \mathrm{m}$ coated with the 110-nm $\mathrm{Pd} / \mathrm{Ag}$ composite film, and (d) central wavelength shift FBG-125 $\mu \mathrm{m}$, FBG-38 $\mu \mathrm{m}$, and FBG-20.6 $\mu \mathrm{m}$ coated with the $110-\mathrm{nm}$ Pd/Ag composite film under different hydrogen concentrations.

As depicted in Figs. 5(a), 5(b), and 5(c), the response time of the FBG coated with the 110-nm $\mathrm{Pd} / \mathrm{Ag}$ composite film is $280 \mathrm{~s}-300 \mathrm{~s}$. The ambient temperature can affect the FBG hydrogen sensor sensitivity in two ways. On one hand, the change in ambient temperature can cause the wavelength shift of the sensing FBG, leading to the reduction of the sensor's accuracy, which may has a bad effect on the sensor sensitivity. However, this adverse effect can be greatly reduced by using a reference FBG $[16,24$, 26 , 27]. On the other hand, lower ambient temperature can decrease the diffusion speed of the hydrogen molecule [12, 13], which increase the response time of the FBG hydrogen sensor. As it is reported, the FBG coated with the 350-nm Pd film without laser heating has no response to $10 \% \mathrm{H}_{2}$ at $-25{ }^{\circ} \mathrm{C}$ ambient temperature [13]. Under high humdity atmosphere, the adsorbed $\mathrm{H}_{2} \mathrm{O}$ on the surface hydrogen sensitive film can reduce the formation of $\mathrm{PdH}_{x}$, desensitizing the hydrogen sensitive film towards the detection of hydrogen [28]. Moreover, the adsorbed $\mathrm{H}_{2} \mathrm{O}$ reduces the hydrogen atoms diffusion rate so that the hydrogen sensor's response time will be increased. High ambient humidity has a bad effect on the sensor's sensitivity and response rate. In our experiment, the longer response time may be mainly attributed to $61.7 \%$ ambient humidity and relatively low temperature.

Figure 5(d) shows the central wavelength shift of the FBG coated with the $110-\mathrm{nm} \mathrm{Pd} / \mathrm{Ag}$ composite film under different concentrations hydrogen. All FBGs coated with the hydrogen sensitive film shift to the longer wavelength with an increase in the hydrogen concentration. FBG hydrogen sensors show the linearity response for $1.5 \%-4 \%$ hydrogen concentrations. However, FBG- $125 \mu \mathrm{m}$ coated with the $\mathrm{Pd} / \mathrm{Ag}$ composite film almost has no wavelength 
shift during $1 \%$ hydrogen exposure. When the hydrogen concentration is $4 \%$ in volume percentage, the wavelength shifts of FBG- $125 \mu \mathrm{m}$, FBG- $38 \mu \mathrm{m}$, and FBG-20.6 $\mu \mathrm{m}$ are $8 \mathrm{pm}, 23 \mathrm{pm}$, and $40 \mathrm{pm}$, respectively. Because of the different etching contents of the fiber, FBG- $125 \mu \mathrm{m}, \mathrm{FBG}-38 \mu \mathrm{m}$, and FBG-20.6 $\mu \mathrm{m}$ have different sensitivities to hydrogen. The FBG with fewer diameters has the higher sensitivity. Compared to FBG-125 $\mu \mathrm{m}$, FBG-20.6 $\mu \mathrm{m}$ can increase the sensitivity by $400 \%$, and the FBG hydrogen sensitivity can be significantly improved by etching the FBG to a proper content.

\section{Fiber optic hydrogen sensors with $\mathrm{Pd} / \mathrm{Ni}$ composite films}

The hydrogen sensitive material plays a key role on the performance of the FBG hydrogen sensor. Hydrogen sensors based on the pure Pd film are easily suffered from Pd film's fatal fracture caused by its $\alpha-\beta$ phase transition. By alloying Pd with other metals such as Ag [29], Mg [30], Pt [31], Au [32], and $\mathrm{Ni}$ [33], the structure stability of hydrogen sensitive films can be improved. Among these Pd alloys, the $\mathrm{Pd} / \mathrm{Ni}$ composite films may be an ideal candidate due to its durability, fast response, and relatively low cost. It has been demonstrated that the $\mathrm{Pd}_{92} / \mathrm{Ni}_{8}$ composite film has the good repeatability during the hydrogen response. Therefore, the $\mathrm{Pd} / \mathrm{Ni}$ composite film with the similar constitution is chosen as the hydrogen sensitive film to overcome the hysteretic effect of the pure Pd film. The Ni film is employed as the basal layer to improve the adhesion between the $\mathrm{Pd} / \mathrm{Ni}$ composite film and FBG. Reducing FBG's diameter by the chemicallyetching process is a simple and effective method to increase the hydrogen sensor's sensitivity [34].

The 110-nm $\mathrm{Pd} / \mathrm{Ni}$ composite thin film was deposited on the etched FBG fiber by using a BESTECH sputtering system. Before preparing the hydrogen sensitive film, the $10-\mathrm{nm} \mathrm{Ni}$ film was deposited on the side-face of the FBG by the RF sputtering process. Under the 0.5-Pa sputtering pressure of $\mathrm{Ar}$, the deposition powers for $\mathrm{Pd}$ and $\mathrm{Ni}$ targets were $100 \mathrm{~W}$ and $50 \mathrm{~W}$, respectively, which corresponded to the deposition rates of $0.14 \mathrm{~nm} / \mathrm{s}$ and $0.01 \mathrm{~nm} / \mathrm{s}$, respectively. With this sputtering process, the atomic ratio of $\mathrm{Pd}$ and $\mathrm{Ni}$ was about 91:9 in the $\mathrm{Pd} / \mathrm{Ni}$ composite film. During the sputtering process, the thickness of the hydrogen sensitive film was monitored by the quartz crystal method. Deposition time for the 10-nm pure Ni film was about $1000 \mathrm{~s}$, and that for the $110-\mathrm{nm} \mathrm{Pd} / \mathrm{Ni}$ composite film was approximately $735 \mathrm{~s}$. Meanwhile, coatings on several $10 \mathrm{~mm} \times 10 \mathrm{~mm}$ Si pieces were also prepared in the same run for the further characterization.

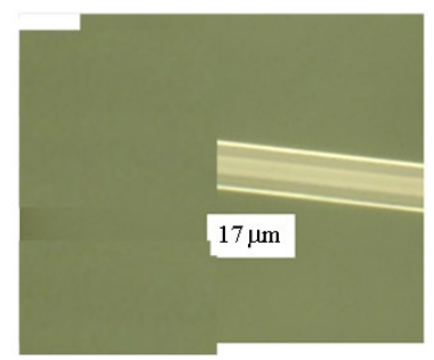

(a)

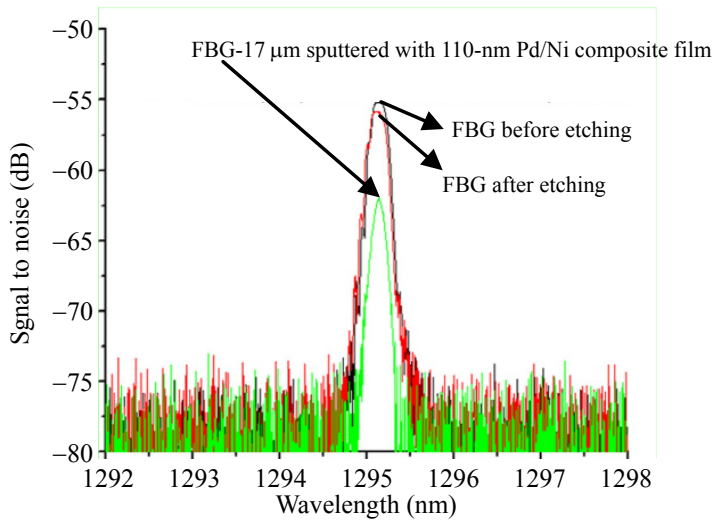

(b)

Fig. 6 FBG spectra under different stages: (a) microphotography of the chemically etched FBG and (b) reflective spectrums of the FBG at different stages.

Figure 6(a) shows the microphotography of the FBG after etched by the HF solution. Obtained by a VHX-100 digital microscope, the diameter of the FBG is approximately $17 \mu \mathrm{m}$ after the etching process. Figure 6 (b) displays the reflective spectra of the FBG at different stages when the room temperature is $23{ }^{\circ} \mathrm{C}$. It can be found that there is not 
much difference between spectra before and after etched by the HF solution. After sputtered with the $\mathrm{Pd} / \mathrm{Ni}$ composite film, a lower intensity and narrower bandwidth of the FBG spectrum can be concluded. This phenomenon may be attributed to the relatively high optical absorption and refractive index of the $\mathrm{Pd} / \mathrm{Ni}$ composite film. However, it can be found that there is no significant shift in the central wavelength of the FBG, which means the central wavelength of the etched FBG is not sensitive to the ambient refractive index. Therefore, the refractive index change of the $\mathrm{Pd} / \mathrm{Ni}$ composite film can be neglected during the hydrogen response.

The elemental analysis of the $\mathrm{Pd} / \mathrm{Ni}$ composite film deposited on the etched FBG was carried out by EDAX. Only Pd and Ni elements were calculated in our experiment. The EDAX result showed the atom ratio of $\mathrm{Pd}: \mathrm{Ni}$ was about $81: 19$, which was consistent with the actual Pd:Ni of the 100-nm $\mathrm{Pd}_{91} / \mathrm{Ni}_{9}$ composite film and $10-\mathrm{nm}$ pure $\mathrm{Ni}$ film. XRD patterns of the $\mathrm{Pd} / \mathrm{Ni}$ composite film at three stages were measured. To observe the obvious phase change, the $\mathrm{Pd} / \mathrm{Ni}$ composite film deposited on the $\mathrm{Si}$ substrate was set in the pure hydrogen atmosphere for 30 minutes before the second XRD measurement. As shown in Fig. 7(b), there are four $\mathrm{Pd} / \mathrm{Ni}$ characteristic peaks (JCPDS 65-6174) in each XRD diffraction spectrum. The as-deposited $\mathrm{Pd} / \mathrm{Ni}$ composite film has relatively sharp peaks at $2 \theta=$ $40.7^{\circ}, 47.7^{\circ}, 69.1^{\circ}$, and $83.4^{\circ}$, while for the hydrogen-absorbed $\mathrm{Pd} / \mathrm{Ni}$ composite film, they locate at $39.6^{\circ}, 46.2^{\circ}, 67.6^{\circ}$, and $82^{\circ}$. Owing to the diffusion of hydrogen atoms, a weaker and wider XRD spectrum of the $\mathrm{Pd} / \mathrm{Ni}$ composite film can be seen in Fig. 7(b), demonstrating that the atom arrangement of the hydrogen-absorbed film transforms toward a relatively disordered state. XRD peaks of the $\mathrm{Pd} / \mathrm{Ni}$ composite film shifts to lower degrees obviously when it absorbs hydrogen, which proves that the lattice constant increase significantly during the hydrogen response. After the hydrogen releasing process, the XRD spectrum can return to its initial state. The XRD results demonstrate the $\mathrm{Pd} / \mathrm{Ni}$ composite film has a good structure stability during the phase transition process.

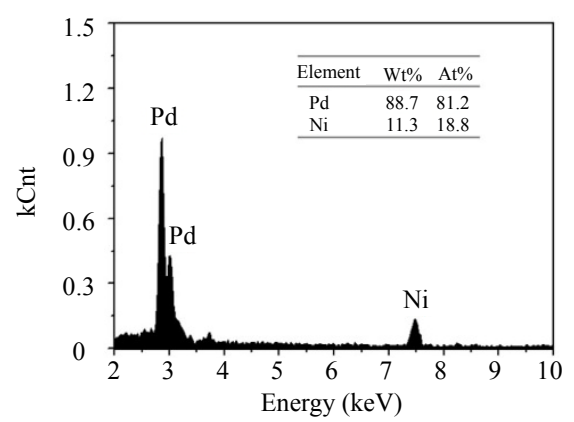

(a)

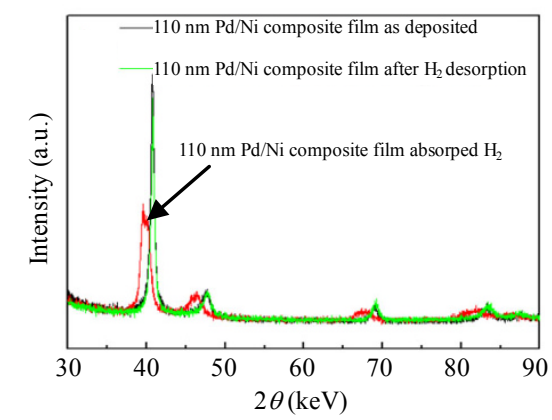

(b)

Fig. 7 Changes of XRD pattern under different stages: (a) EDAX pattern of the 110-nm Pd/Ni composite film, and (b) X-ray diffractions of the $110-\mathrm{nm} \mathrm{Pd} / \mathrm{Ni}$ composite film deposited on the Si substrate at different stages.

Figure 8(a) illustrates the hydrogen response of the etched FBG coated with the $110-\mathrm{nm} \mathrm{Pd} / \mathrm{Ni}$ composite film under different hydrogen concentrations. The FBG is also sensitive to the ambient temperature. Using a reference $\mathrm{FBG}$ for temperature compensation is a simple way for FBG sensors. At the room temperature of $23{ }^{\circ} \mathrm{C}$, the central wavelength of the sensing FBG in our experiment was about $1295.168 \mathrm{~nm}$, and that of the reference FBG was about $1307.493 \mathrm{~nm}$. The relative wavelength was derived by subtracting the central wavelength of the reference FBG from that of the sensing FBG. The change of $0 \% \mathrm{H}_{2}$ baseline was mainly due to the central wavelength fluctuation of etched FBG. When the hydrogen concentrations were $2 \%, 3 \%, 3.5 \%$, and $4 \%$, the wavelength shifts of the etched FBG were $33 \mathrm{pm}, 45 \mathrm{pm}, 52 \mathrm{pm}$, and $60 \mathrm{pm}$, respectively. Response time was calculated 
from the hydrogen flowing into the gas room to FBG reaching $90 \%$ wavelength shift. However, the response time for $2 \%$ hydrogen concentration was 4 minutes -5 minutes, which was much longer than the reported results [33]. The reason for this phenomenon is that our proposed hydrogen sensor is based on the volume expansion of the $\mathrm{Pd} / \mathrm{Ni}$ composite film. Only the $\mathrm{Pd}-\mathrm{H}$ phase reaches balance under certain hydrogen concentration, and the volume expansion caused by hydrogen atoms diffusion can be maintained, resulting that the FBG reaches the maximum wavelength shift. With air as carrier gas, the formation of the water molecule [35] on the surface of the $\mathrm{Pd} / \mathrm{Ni}$ composite film may be another factor for the retardation in the response rate. $\mathrm{Ni}$ can be easily oxidized in air, which can slow down the hydrogen atoms diffusion rate, leading to an increase in the hydrogen sensor's response time. Therefore, the oxidization of Ni has a bad effect on the hydrogen sensor's response rate. Using Pt or $\mathrm{Pd} / \mathrm{Pt}$ alloys [36] as the protective layer may improve the stability and response time of hydrogen sensitive films. Figure 8 (b) depicts five cycles of hydrogen response of the etched FBG coated with the $110-\mathrm{nm} \mathrm{Pd} / \mathrm{Ni}$ composite film under the $4 \%$ hydrogen concentration. During the five cycle's response, the sensor shows the good repeatability. There is little hysteretic effect during the hydrogen response. This can be attributed to the good mechanical strength of the $\mathrm{Pd} / \mathrm{Ni}$ composite film. Since $\mathrm{Ni}$ has better ductility and good adhesion towards the optic fiber, the adhesion between the etched $\mathrm{FBG}$ and $\mathrm{Pd} / \mathrm{Ni}$ composite film can be improved by using $\mathrm{Ni}$ as the basal layer. By alloying $\mathrm{Pd}$ with $\mathrm{Ni}$, the lattice change between $\alpha$ phase and $\beta$ phase can be reduced. The volume expansion caused by the phase change can be controlled at a proper value, and the $\mathrm{Pd} / \mathrm{Ni}$ composite film can recover to its initial structure after the hydrogen exposure. Therefore, the FBG hydrogen sensor's reversibility can be improved by using the $\mathrm{Pd} / \mathrm{Ni}$ composite film.

Figure 9 displays the wavelength shift of hydrogen under different hydrogen concentrations. The fluctuation of the wavelength shift of the FBG is about $3 \mathrm{pm}-4 \mathrm{pm}$. An error bar about $4 \mathrm{pm}$ has been displayed in Fig. 7. When hydrogen concentrations are $1 \%, 2 \%, 3 \%$, and $4 \%$ in volume ratio, the corresponding wavelength shifts of the etched FBG are $15 \mathrm{pm}, 33 \mathrm{pm}, 45 \mathrm{pm}$, and $60 \mathrm{pm}$, respectively. The wavelength shift of the etched FBG increases linearly with an increase in the hydrogen concentration.

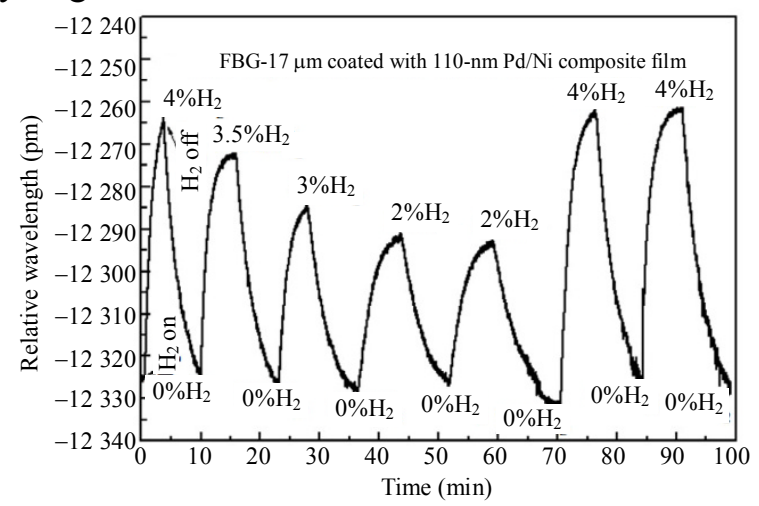

(a)

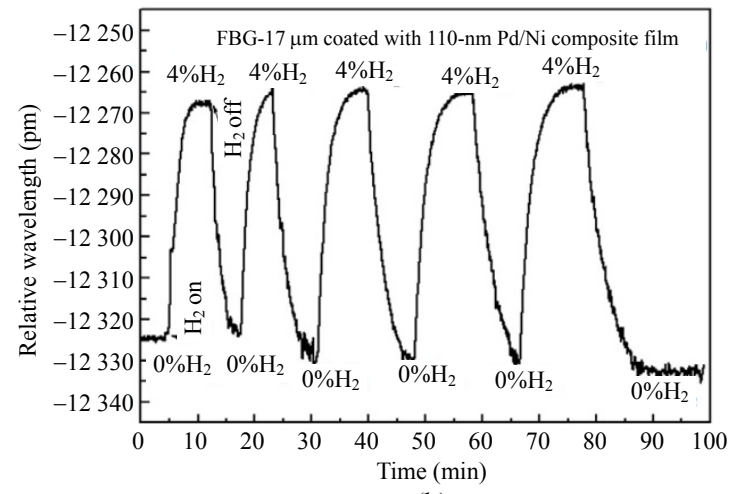

(b)

Fig. 8 Response to different hydrogen concentrations: (a) etched FBG coated with the 110-nm Pd/Ni composite film under different hydrogen concentrations and (b) five cycles of hydrogen response of the etched FBG coated with the 110-nm $\mathrm{Pd} / \mathrm{Ni}$ composite film.

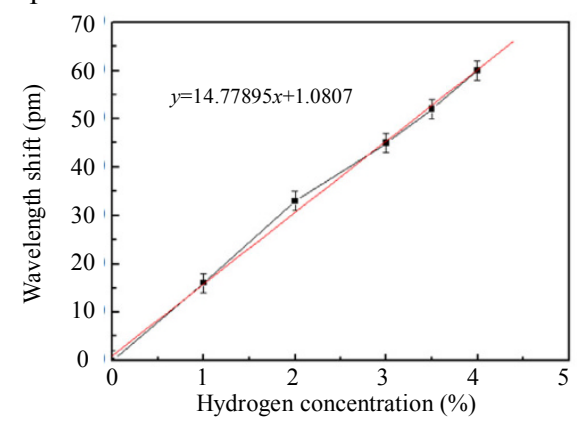

Fig. 9 Wavelength shifts of the etched FBG under different hydrogen concentrations. 
The sensitivity of the Pd composite film coated FBG hydrogen sensor still needs to be improved to meet the demand of the application. Recently, electron devices based on the flexible substrate have attracted numerous research efforts due to their excellent performance. By using the flexible substrate, the mechanical strength and electrical stability of the devices can be greatly enhanced. As shown in Fig. 10, the polypropylene sheet is employed as a flexible substrate to protect the etched FBG because of its good stability and hydrophobicity, and the sensitivity of the FBG hydrogen sensor can be increased due to its low Young's modulus.

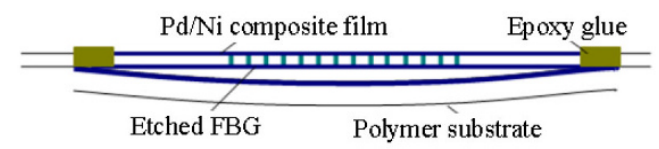

Fig. 10 Schematic illustration of the sensing section of the FBG hydrogen sensor.

The Pd/Ni composite film was sputtered on the etched FBG and polypropylene sheet by using a BESTECH sputtering system. The hydrogen sensing performance was carried out at room temperature of $25{ }^{\circ} \mathrm{C}$ using air as carrier gas.

Figure 11(a) shows the microphotography of the etched FBG by the HF solution. Obtained by the VHX-100 digital microscope, the diameter of the FBG is approximately $21 \mu \mathrm{m}$ after the etching process. As it is shown in Fig. 11(b), the surface of the etched FBG is covered with the hydrogen sensitive film. Generally, the FBG with the smaller diameter has the higher sensitivity when coated with the same thickness hydrogen sensitive film. However, the optical power in the single mode fiber will be reduced if the residual diameter of the FBG is too small. In our previous work, FBG-17 $\mu \mathrm{m}$ coated with the hydrogen sensitive film caused the power loss in the optical fiber [37], which had a bad effect on the hydrogen concentration distributed measurement. According the reported result [38], the central wavelength of the FBG will not be affected by the external refractive index when its residual diameter is more than $20 \mu \mathrm{m}$. It is demonstrated that the FBG with a diameter of $20.6 \mu \mathrm{m}$ has less optical power loss when it is coated with the $\mathrm{Pd} / \mathrm{Ag}$ composite film [39]. Therefore, the diameter of the etched FBG should be controlled at about $20 \mu \mathrm{m}$. The FBG with a diameter of $21 \mu \mathrm{m}$ was prepared by dipped in the $50 \% \mathrm{HF}$ solution for 49 minutes to remove the cladding layer. It can be seen from Fig. 11(c) that there is almost no difference between the reflected spectra of the FBG at different stages, which proves FBG-21 $\mu \mathrm{m}$ has no optical power loss after sputtered with the $\mathrm{Pd} / \mathrm{Ni}$ composite film. The sample shown in Fig. 11(d) reveals the polypropylene sheet is uniformly coated with the $\mathrm{Pd} / \mathrm{Ni}$ composite film, and the etched $\mathrm{FBG}$ is properly protected and easy for operation.

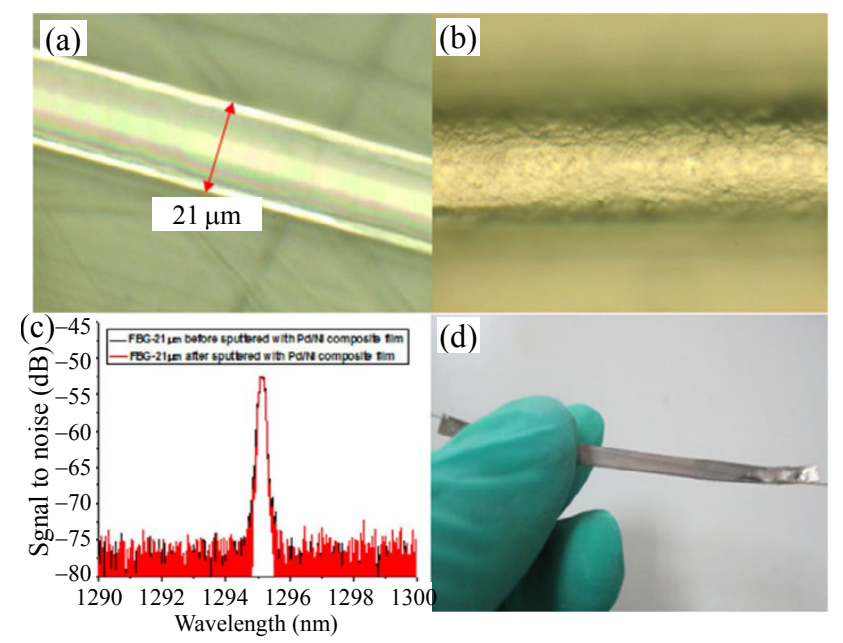

Fig. 11 Microphotography of the etched FBG (a) before and (b) after sputtered with $\mathrm{Pd} / \mathrm{Ni}$ composite film, (c) reflective spectra of the FBG at different stages, and (d) image of the sensing probe of the FBG hydrogen sensor.

As shown in Figs. 12(a) and 12(b), the FBG hydrogen sensor presents a good repeatability under $2 \%$ and $4 \%$ hydrogen concentrations at the room temperature of $25{ }^{\circ} \mathrm{C}$. The wavelength shift of the FBG hydrogen sensor toward $2 \%$ and $4 \%$ hydrogen are $66 \mathrm{pm}$ and $146 \mathrm{pm}$, respectively. Response time is calculated from the hydrogen flowing into the gas room to FBG reaching $90 \%$ wavelength shift, while the recovery time starts at the $\mathrm{Pd} / \mathrm{Ni}$ composite film being exposed to the air and ends at FBG decreasing $90 \%$ wavelength shift. The response time of the FBG hydrogen sensor toward $4 \%$ is 5 minutes 6 minutes. The recovery time of the FBG hydrogen 
sensor is close to its response time. The reason for this phenomenon is mainly due to the thicker $\mathrm{Pd} / \mathrm{Ni}$ composite film. However, the wavelength shift of the FBG hydrogen sensor toward $4 \%$ hydrogen is about $143 \%$ more than that of FBG- $17 \mu$ m coated

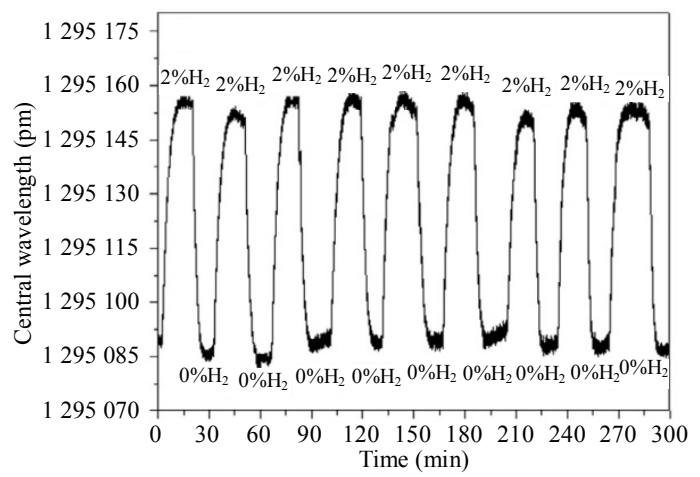

(a)

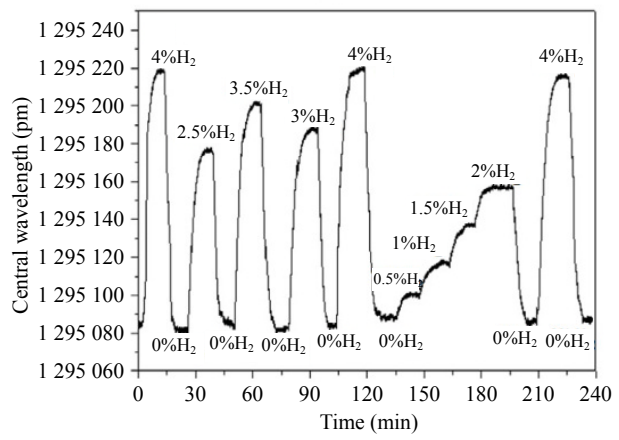

(c) 110-nm $\mathrm{Pd} / \mathrm{Ni}$ composite films. Nevertheless, FBG-21 $\mu \mathrm{m}$ coated with the $140-\mathrm{nm} \quad \mathrm{Pd} / \mathrm{Ni}$ composite films has little optical power loss, which can ensure its distributed measurement capability.

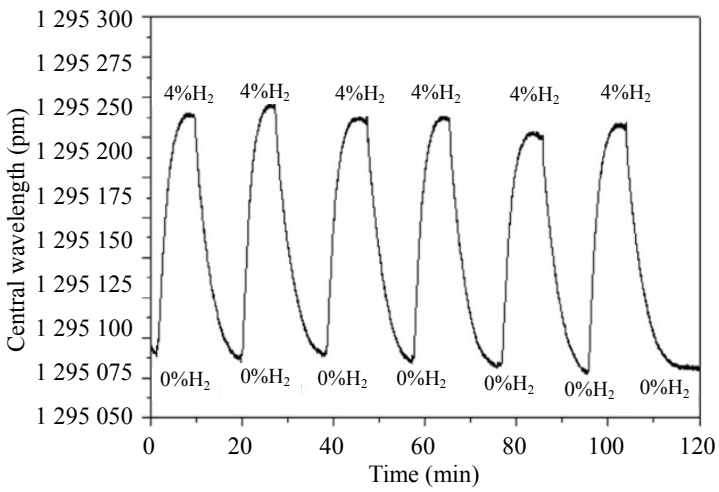

(b)

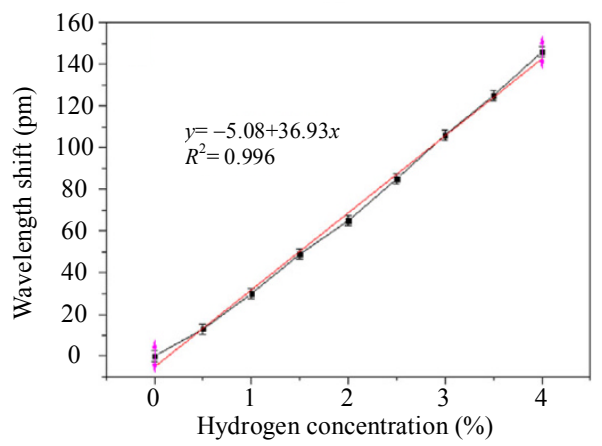

(d)

Fig. 12 Response to different hydrogen concentrations: (a) nine cycles of the FBG hydrogen sensor toward 2\% hydrogen, (b) seven cycles of the FBG hydrogen sensor toward 4\% hydrogen, (c) hydrogen response of the FBG hydrogen sensor under different hydrogen concentrations, and (d) wavelength shifts of the FBG hydrogen sensor under different hydrogen concentrations.

Figure 12(c) shows the hydrogen response of the FBG under different hydrogen concentrations. When hydrogen concentrations are $0.5 \%, 1 \%, 1.5 \%, 2 \%$, $2.5 \%, 3 \%, 3.5 \%$, and $4 \%$, wavelength shifts of the FBG are $13 \mathrm{pm}, 30 \mathrm{pm}, 49 \mathrm{pm}, 65 \mathrm{pm}, 85 \mathrm{pm}, 106 \mathrm{pm}$, $125 \mathrm{pm}$, and $146 \mathrm{pm}$, respectively. Figure $12(\mathrm{~d})$ plots the curve fitting of the wavelength shift of the FBG hydrogen sensor under different hydrogen concentrations. It can be concluded that the FBG shifts linearly with an increase in hydrogen concentrations. The fluctuation of the wavelength shift of the FBG is $3 \mathrm{pm}-5 \mathrm{pm}$, and an error bar about $5 \mathrm{pm}$ has been displayed in Fig. 12(d). Compared to the previous work [39], the sensitivity of the FBG hydrogen sensor is significantly enhanced due to the utilization of the flexible substrate. The sensing mechanism of the proposed FBG hydrogen sensor results from the $\mathrm{Pd} / \mathrm{Ni}$ composite film swelling and induces a stress on the grating. The wavelength shift of the FBG hydrogen sensor is based on the stress that is induced on the etche d FBG.

The wavelength shift of the etched FBG coated with the Pd film is expressed by (2) in [40], where $p$ is the hydrogen partial pressure, $k$ is Sievert's coefficient, $a$ is the diameter of the FBG before the Pd film coating, $b$ is the diameter of the FBG after coated with the $\mathrm{Pd}$ film, $Y_{F}$ is Young's modulus of the optical fiber, $Y_{\mathrm{Pd}}$ is Young's modulus of the Pd film, and $\lambda_{B}$ is the central wavelength of the FBG. For the FBG sputtered with the $\mathrm{Pd} / \mathrm{Ni}$ composite film, the wavelength shift can 
be expressed by (3), where $Y_{\mathrm{PdNi}}$ is Young's modulus of the $\mathrm{Pd} / \mathrm{Ni}$ composite film. For the configuration of the FBG with the polypropylene substrate, the wavelength shift of the FBG can be crudely given by (4) if the polypropylene substrate expands homogeneously during the hydrogen response. In (4), $w_{p p}$ is the width of the polypropylene substrate, $t_{p p}$ is the thickness of the polypropylene substrate, and $t_{\mathrm{Pd} N \mathrm{Ni}}$ is the thickness of the $\mathrm{Pd} / \mathrm{Ni}$ composite film.

$$
\begin{aligned}
& \Delta \lambda_{B}=0.026 \frac{\sqrt{p}}{k}\left[\frac{\left(b^{2}-a^{2}\right) Y_{\mathrm{Pd}}}{a^{2} Y_{F}+\left(b^{2}-a^{2}\right) Y_{\mathrm{Pd}}}\right] \times 0.78 \lambda_{B} \\
& \Delta \lambda_{B 1}=0.026 \frac{\sqrt{p}}{k}\left[\frac{\left(b^{2}-a^{2}\right) Y_{\mathrm{Pd} / \mathrm{Ni}}}{a^{2} Y_{F}+\left(b^{2}-a^{2}\right) Y_{\mathrm{Pd} N \mathrm{i}}}\right] \times 0.78 \lambda_{B} \\
& \Delta \lambda_{B 2}= \\
& 0.026 \frac{\sqrt{p}}{k}\left[\frac{\pi}{4}\left(b^{2}-a^{2}\right) Y_{\mathrm{Pd} N \mathrm{i}}+w_{p p} t_{\mathrm{Pd} / \mathrm{Ni}} Y_{\mathrm{Pd} / \mathrm{Ni}}\right] \times 0.78 \lambda_{B} \\
& \frac{\pi}{4} a^{2} Y_{F}+\frac{\pi}{4}\left(b^{2}-a^{2}\right) Y_{\mathrm{Pd} \mathbb{N i}}+w_{p p} t_{\mathrm{Pd} \mathbb{N i}} Y_{\mathrm{Pd} / \mathrm{Ni}}+w_{p p} t_{p p} Y_{p p} .
\end{aligned}
$$

The computed result shows that the sensitivity of the FBG hydrogen sensor can be significantly increased by using the polypropylene sheet as the protective substrate.

It can be theoretically proved that the proposed sensitivity enhancement by using the flexible substrate is effective. Actually, when hydrogen is flowing into the gas room, the polypropylene sheet can have much more deformation due to its smaller Young's modulus. Therefore, the stress induced on the FBG will be enhanced, which will greatly increase the sensitivity of the FBG hydrogen sensor.

The calculated wavelength shift of the sensor for $4 \%$ hydrogen is $58 \mathrm{pm}$, which is much smaller than $146 \mathrm{pm}$. The reason for this phenomenon may be mainly due to the higher hydrogen content in the thin hydrogen sensitive film [40]. In Sutapum's work, it was reported that the stress in the thin Pd film was three times higher than that found in bulk $\mathrm{Pd}$. The calculated wavelength shift of our sensor is computed by imputing induced stress of bulk Pd. However, the wavelength shift of our sensor is no more than three times of the calculated result, which can be attributed to the lower hydrogen absorption capability of the $\mathrm{Pd} / \mathrm{Ni}$ composite film [41, 42].

To explore the stability and repeatability of the FBG hydrogen sensor, the sensor was exposed to hydrogen after six-month storage in air. Figure 13 depicts four cycles of the FBG hydrogen sensor under the $4 \%$ hydrogen concentration. The wavelength shift of the FBG hydrogen sensor is about $143 \mathrm{pm}$, which is slightly less than its previous value. This experimental results show the FBG hydrogen sensor still has the good sensitivity and repeatability. The change of $0 \% \mathrm{H}_{2}$ baseline can be attributed to an increase in the ambient temperature. However, the response time of the FBG hydrogen sensor increases to 10 minutes, which is much longer than its initial value. One reason for the slower response rate of the FBG hydrogen sensor is the oxidization of the $\mathrm{Pd} / \mathrm{Ni}$ composite film. The adsorption of the water molecule [43] on the surface of the hydrogen sensitive film can be another factor for an increase in the response time.

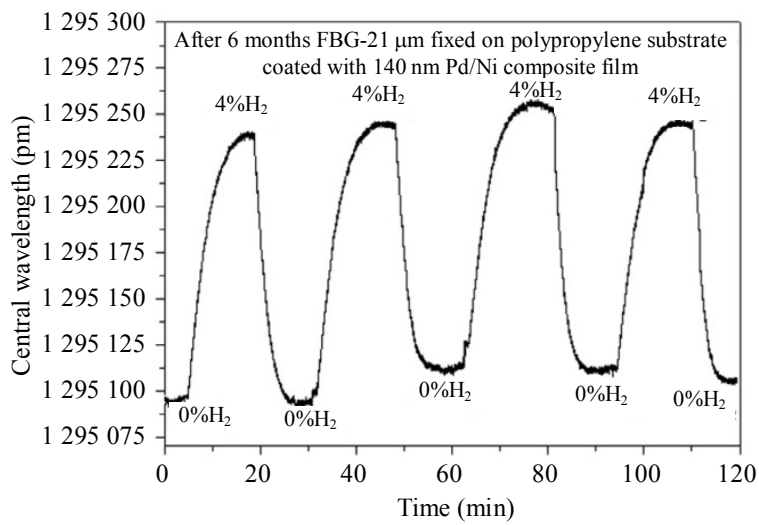

Fig. 13 Four cycles of hydrogen response of the FBG hydrogen sensor.

The drawback of the FBG hydrogen sensor is its slow response time. The slower response time of the FBG sensor is mainly attributed to the thicker $\mathrm{Pd} / \mathrm{Ni}$ composite film and the oxidization of the $\mathrm{Pd} / \mathrm{Ni}$ composite film. One method to overcome this drawback is to employ the polymer miro-fiber FBG [44] as the sensing element, thus we can sputter the thinner $\mathrm{Pd} / \mathrm{Ni}$ composite on the surface of the FBG 
without sacrificing the sensitivity of the FBG hydrogen sensor. Therefore, the response time of the sensor can be reduced. The second method is to prepare $\mathrm{Pd} / \mathrm{Pt}$ as the hydrogen sensitive film, which may improve the diffusion rate of the hydrogen atom since $\mathrm{Pd} / \mathrm{Pt}$ can be a highly efficiency catalyst material [45, 46]. At last, depositing Pt or Pd/Pt [47] as the protective layer may inhibit the oxidization of the hydrogen sensitive film, which can ensure the response rate of the hydrogen sensitive film. Although the response time of the sensor increases, the sensitivity of the FBG hydrogen sensor can be maintained. Therefore, the etched FBG can be used for hydrogen concentration measurement by depositing the hydrogen sensitive film as the protective layer.

\section{Fiber optic hydrogen sensors with $\mathrm{Pt} / \mathrm{WO}_{3}$ coatings}

Currently, two types of FBG hydrogen sensors have been reported. The first type of the FBG hydrogen sensor is based on the volume change of $\mathrm{Pd}$ or Pd alloys during the hydrogen response. Another type is based on Pt-loaded $\mathrm{WO}_{3}$ coatings undergoing an exothermic reaction in the hydrogen atmosphere. The FBG hydrogen sensor based on the Pt-loaded $\mathrm{WO}_{3}$ coating has the higher sensitivity, but its performance will be decreased if there has little oxygen in the ambient atmosphere. Some special facilities, such as the nuclear waste tank, may have little oxygen in it and needs monitoring the hydrogen concentration.

Caucheteur et al. [48] reported the most sensitive FBG hydrogen sensor based on the Pt-loaded $\mathrm{WO}_{3}$ coating with an exothermic reaction in the hydrogen atmosphere. Although the sensor has the fast response and high sensitivity, it has no response towards hydrogen below $6000 \mathrm{ppm}$ due to the limitation of hydrogen sensitive materials. Another disadvantage for this FBG hydrogen sensor is that the Pt-loaded $\mathrm{WO}_{3}$ coating may be detached from the surface of the FBG during the hydrogen response. To overcome these shortcomings, several new ideas have been proposed. Firstly, the preparation process of the Pt-loaded $\mathrm{WO}_{3}$ coating was optimized so the FBG hydrogen sensor could response to the lower concentration of hydrogen. Secondly, the FBG sensor was encapsulated in a glass-matrix strip with much the higher thermal expansion coefficient. Therefore, the temperature sensitivity of the FBG could be increased. The glass-matrix strip has a slim groove for holding the Pt-loaded $\mathrm{WO}_{3}$ coating, which can prevent the shedding of the hydrogen sensitive coating. The FBG hydrogen sensor was prepared by combining performance-improved Pt-loaded $\mathrm{WO}_{3}$ coating with the temperature sensitivity-enhanced FBG structure.

$\mathrm{WO}_{3}$ precursor was prepared by the sol-gel method, and $\mathrm{H}_{2} \mathrm{PtCl}_{6} \cdot 6 \mathrm{H}_{2} \mathrm{O}$ was added in $\mathrm{WO}_{3}$ precursor for generating catalyst $\mathrm{Pt}$. The mixture was stirred by the magnetic stirrer at $80{ }^{\circ} \mathrm{C}$ for 5 hours to remove the water for the annealing process. With a thermal treatment under the temperature of $315{ }^{\circ} \mathrm{C}$ for one hour, $\mathrm{Pt} / \mathrm{WO}_{3}$ powder was prepared for the next process. After the annealing process, Pt-loaded $\mathrm{WO}_{3}$ powder was mixed with appropriate de-ionized water and then was uniformly deposited on the grating section of the FBG for the hydrogen response. Meanwhile, Pt-loaded $\mathrm{WO}_{3}$ coatings on several $10 \mathrm{~mm} \times 10 \mathrm{~mm} \mathrm{Si}$ pieces were also prepared for the further characterization. In this paper, three kinds of Pt-loaded $\mathrm{WO}_{3}$ powders were prepared by adding $0.15 \mathrm{~g}, 0.3 \mathrm{~g}$, and $0.5 \mathrm{~g} \mathrm{H}_{2} \mathrm{PtCl}_{6} \cdot 6 \mathrm{H}_{2} \mathrm{O}$ in the same amount $\mathrm{WO}_{3}$ precursor, and the corresponding coatings were defined as Pt-loaded $\mathrm{WO}_{3}$ coating 1, Pt-loaded $\mathrm{WO}_{3}$ coating 2, and Pt-loaded $\mathrm{WO}_{3}$ coating 3, respectively. Equal qualities of three Pt-loaded $\mathrm{WO}_{3}$ coatings were uniformly deposited on FBG1, FBG2, and FBG3, respectively.

The hydrogen sensing performance was carried out at the room temperature of $25{ }^{\circ} \mathrm{C}$ using air as carrier gas. The relative humidity of the atmosphere was about $52.4 \%$. 
The Pt-loaded $\mathrm{WO}_{3}$ coating X-ray diffraction pattern was obtained on an X-ray diffractometer (XRD D8 Advance, Brucker, German) using the $\mathrm{Cu}$ $\mathrm{K} \alpha$ radiation source operating at $40 \mathrm{kV}$ and $30 \mathrm{~mA}$. Figure 14 gives the $\mathrm{X}$-ray diffraction patterns of three kinds of Pt-loaded $\mathrm{WO}_{3}$ coatings before hydrogen exposure. It can be observed that the XRD of $\mathrm{WO}_{3}$ has good correspondence with the joint committee on power diffraction standards cards 20-1323 (JCPDS 20-1323), which demonstrates $\mathrm{WO}_{3}$ has the triclinic phase when the annealing temperature is $315{ }^{\circ} \mathrm{C}$. From JCPDS 46-0902, $\mathrm{PtCl}_{2}$ has relatively sharp peaks at $2 \theta=12.8^{\circ}, 13.4^{\circ}$, and 35. $1^{\circ}$. As shown in Fig. 14, the Pt element exists in the Pt-loaded coating in the state of $\mathrm{PtCl}_{2}$ before hydrogen exposure. And $\mathrm{PtCl}_{2}$ peaks gradually become stronger with an increase in $\mathrm{H}_{2} \mathrm{PtCl}_{6} \cdot 6 \mathrm{H}_{2} \mathrm{O}$ in the previous $\mathrm{WO}_{3}$ precursor. After first hydrogen exposure, four Pt peaks at $2 \theta=39.8^{\circ}, 46.2^{\circ}, 67.4^{\circ}$, and $81.2^{\circ}$ (JCPDS 65-2868) can be seen in the Pt-loaded $\mathrm{WO}_{3}$ coating 3 XRD spectrum. This phenomenon indicates most $\mathrm{PtCl}_{2}$ transforms to $\mathrm{Pt}$ after the first hydrogen response, which proves $\mathrm{PtCl}_{2}$ can generate $\mathrm{Pt}$ efficiently in the presence of hydrogen. Moreover, the performance of the Pt-loaded $\mathrm{WO}_{3}$ coating becomes better due to the generation of the Pt catalyst, which is similar to the gasochromic coloring effect of $\mathrm{WO}_{3}$ using $\mathrm{PdCl}_{2}$ as the hydrogen catalyst $[49,50] . \mathrm{H}_{2} \mathrm{PtCl}_{6} \cdot 6 \mathrm{H}_{2} \mathrm{O}$ can transform to $\mathrm{Pt}$ more efficiently under the higher annealing temperature, but the hydrogen sensitivity of the Pt-loaded $\mathrm{WO}_{3}$ coating will decrease due to the crystallization of $\mathrm{WO}_{3}[51,52]$.

The elemental analysis was carried out by energy dispersive X-ray analysis (EDAX) using an X-ray detector attached to the FE-SEM instrument. The composition and morphology of the Pt-loaded $\mathrm{WO}_{3}$ coating were characterized using the field emission scanning electron microscope (FE-SEM S-4800, Hitachi, Japan). As shown in Figs. 14(a), 14(b), and 14(c), the actual ratios of Pt:W in three kinds Pt-loaded $\mathrm{WO}_{3}$ coatings are about 1:16, 1:8, and 1:5, respectively. Figure 14(d) shows the morphology of the Pt-loaded $\mathrm{WO}_{3}$ coating with the molar ratio of $\mathrm{Pt}: \mathrm{W}=1: 5$ after the hydrogen response. It can be seen that the Pt-loaded $\mathrm{WO}_{3}$ coating consists of $\mathrm{WO}_{3}$ nanolamellaes with different squares. The thickness of $\mathrm{WO}_{3}$ nanolamellaes is about $50 \mathrm{~nm}$, which can provide a large surface for the hydrogen response. There are a lot of channels or gaps between nanolamellaes, which can ensure the rapid diffusion of hydrogen molecules in the Pt-loaded $\mathrm{WO}_{3}$ coating. Meanwhile the X-Ray diffraction characterization of these samples demonstrates the micro-crystallized structure of the coating as shown in Fig. 15.
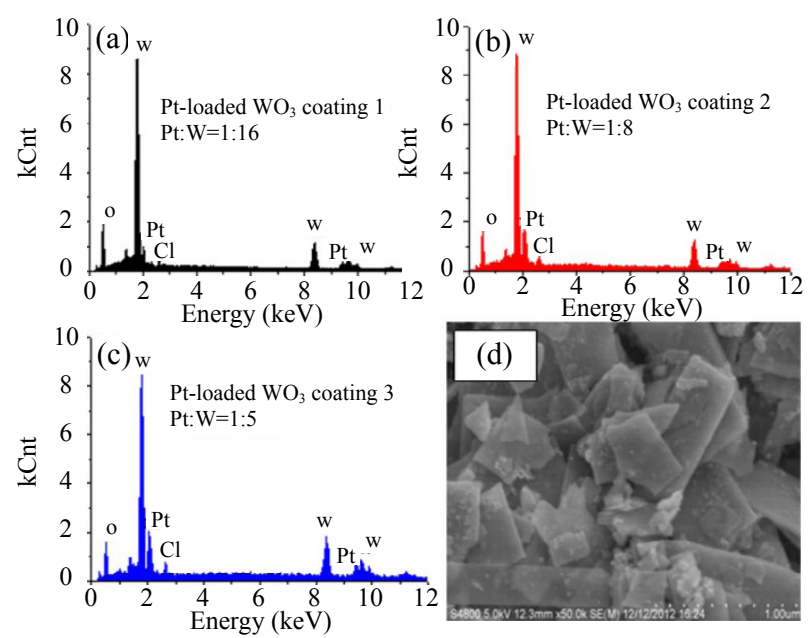

Fig. 14 EDAX pattern of (a) Pt-loaded $\mathrm{WO}_{3}$ coating 1 , (b) Pt-loaded $\mathrm{WO}_{3}$ coating 2, (c) Pt-loaded $\mathrm{WO}_{3}$ coating 3 after hydrogen exposure, and (d) the morphology of Pt-loaded $\mathrm{WO}_{3}$ coating 3 after hydrogen response.

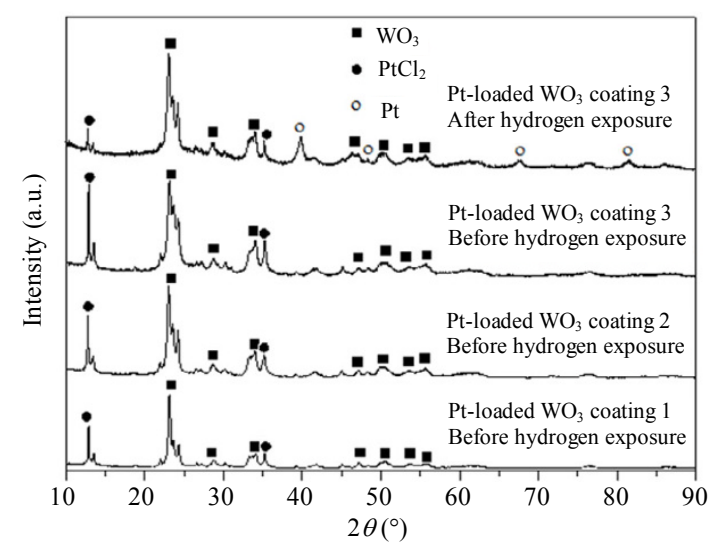

Fig. 15 X-ray diffraction of Pt-loaded $\mathrm{WO}_{3}$ coatings.

As shown in Fig. 16(a), the FBG was fixed on the glass-matrix strip with an etched slim groove so 
that the Pt-loaded $\mathrm{WO}_{3}$ coating could be stably immobilized on the surface near the FBG grating section. The color of the Pt-loaded $\mathrm{WO}_{3}$ coating changed from gray to dark blue during the first hydrogen response. Although the Pt-loaded $\mathrm{WO}_{3}$ coating cannot be restored to its initial color, its thermal effect can be maintained during the hydrogen response. Figure 16(b) shows the morphology of the Pt-loaded $\mathrm{WO}_{3}$ coating after the hydrogen response. It can be concluded that the Pt-loaded $\mathrm{WO}_{3}$ coating consists of $\mathrm{WO}_{3}$ nanolamellaes with different squares. The thickness of the $\mathrm{WO}_{3}$ nano-lamellae is about $50 \mathrm{~nm}$, which provides the large surface for the hydrogen response. In addition, there are a lot of gaps between nano-lamellaes, which can ensure the rapid diffusion of hydrogen molecules in the Pt-loaded $\mathrm{WO}_{3}$ coating.
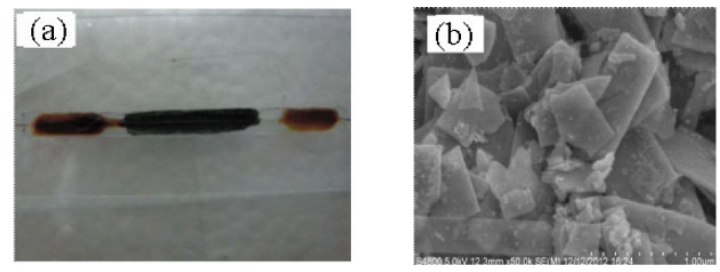

Fig. 16 Hydrogen sensor sample and its microstructure: (a) image of the FBG fixed on the glass-matrix strip deposited with the Pt-loaded $\mathrm{WO}_{3}$ coating after hydrogen response and (b) morphology of the Pt-loaded $\mathrm{WO}_{3}$ coating after the hydrogen response.

Figure 17 illustrates the wavelength shifts of the FBG before [Fig. 17(a)] and after [Fig. 17(b)] fixed on the glass-matrix strip under different temperatures. The temperature sensitivity of the FBG with the central wavelength of $1293 \mathrm{~nm}$ was about $8.465 \mathrm{pm} /{ }^{\circ} \mathrm{C}$. After the $\mathrm{FBG}$ was fixed on the glass substrate, its temperature sensitivity has been increased to $16.273 \mathrm{pm} /{ }^{\circ} \mathrm{C}$. The experimental results demonstrate that the temperature sensitivity of the FBG is nearly doubled after the sensibilization process. Based on the exothermic reaction of the Pt-loaded $\mathrm{WO}_{3}$ coating, the sensitivity of the hydrogen sensor can be increased by employing the FBG with the higher temperature sensitivity.

Figure 18(a) depicts the response of the FBG hydrogen sensor under different hydrogen

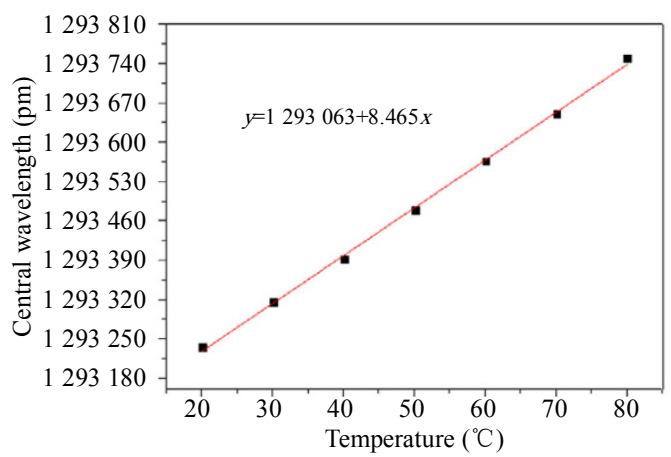

(a)

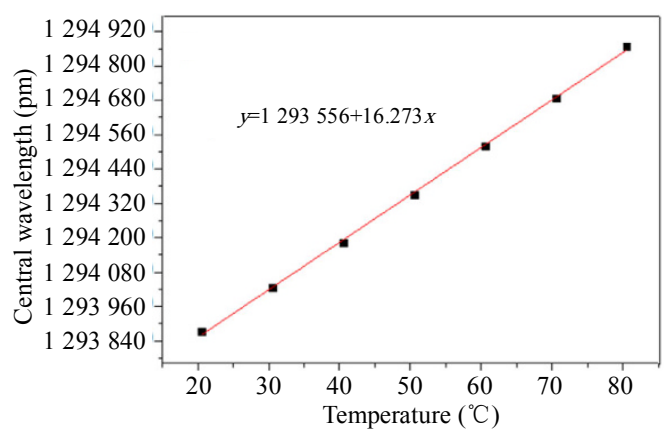

(b)

Fig. 17 Wavelength shift of the FBG (a) before and (b) after fixed on the glass substrate under different temperatures.

concentrations. When the hydrogen concentrations are $8000 \mathrm{ppm}, 7200 \mathrm{ppm}, 6400 \mathrm{ppm}, 6000 \mathrm{ppm}$, $5600 \mathrm{ppm}, 5200 \mathrm{ppm}, 4800 \mathrm{ppm}, 4400 \mathrm{ppm}$, 4000 ppm, 3600 ppm, 3200 ppm, 2800 ppm, 2400 ppm, 2200 ppm, 2000 ppm, 1800 ppm, $1600 \mathrm{ppm}, 1200 \mathrm{ppm}, 800 \mathrm{ppm}, 400 \mathrm{ppm}$, and $200 \mathrm{ppm}$, the wavelength shifts of the FBG are $448 \mathrm{pm}, 385 \mathrm{pm}, 331 \mathrm{pm}, 302 \mathrm{pm}, 283 \mathrm{pm}, 259 \mathrm{pm}$, $233 \mathrm{pm}, 203 \mathrm{pm}, 180 \mathrm{pm}, 153 \mathrm{pm}, 130 \mathrm{pm}, 108 \mathrm{pm}$, $86 \mathrm{pm}, 79 \mathrm{pm}, 68 \mathrm{pm}, 58 \mathrm{pm}, 52 \mathrm{pm}, 40 \mathrm{pm}, 28 \mathrm{pm}$, $12 \mathrm{pm}$, and $5 \mathrm{pm}$, respectively. Compared to the reported work [53], low concentrations hydrogen response capacity of the FBG hydrogen sensor is greatly improved due to the better performance of the Pt-loaded $\mathrm{WO}_{3}$ coating. Response time is calculated from hydrogen flowing into the air chamber to FBG reaching the maximum wavelength shift. The response time of the FBG hydrogen sensor is about 2 minutes, which is much longer than that of the FBG hydrogen sensor deposited with $400{ }^{\circ} \mathrm{C}$ annealed Pt-loaded $\mathrm{WO}_{3}$ coating [54]. The slower response rate of the FBG hydrogen sensor may be attributed to the thicker $\mathrm{WO}_{3}$ nano-lamellaes. 
However, the hydrogen response rate of the Pt-loaded $\mathrm{WO}_{3}$ coating is much quicker than that of the $\mathrm{Pd} / \mathrm{Ni}$ composite film [55]. Figure 18(b) gives the curve fitting of the wavelength shift of the FBG under different hydrogen concentrations. As shown in Fig. 18(b), the central wavelength shift FBG shifts nonlinearly with an increase in hydrogen concentrations, and the curve equation is in good agreement with experimental data.

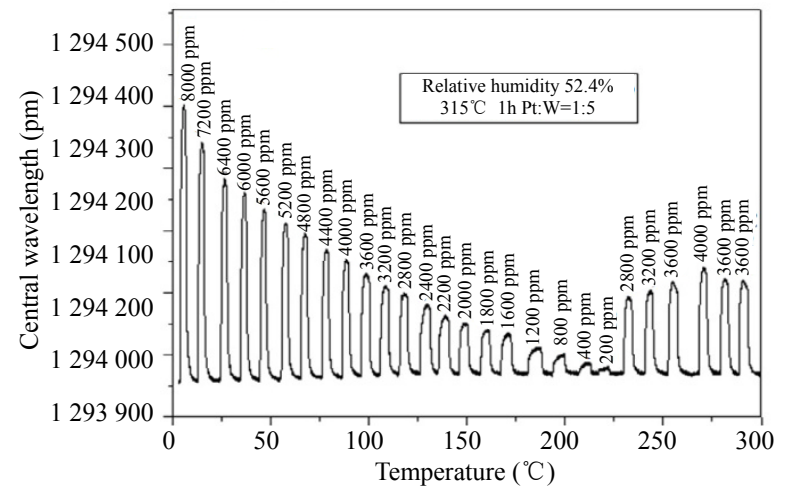

(a)

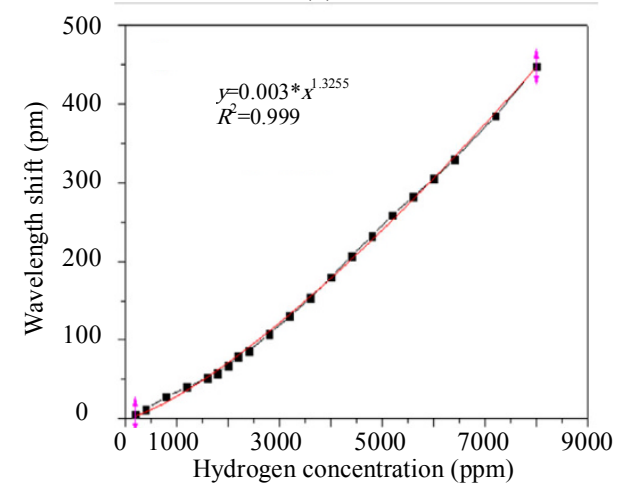

(b)

Fig. 18 Response to different hydrogen concentrations: (a) hydrogen response of the FBG coated with Pt-loaded $\mathrm{WO}_{3}$ and (b) curve fitting wavelength shift of the FBG hydrogen sensor under different hydrogen concentrations.

Figure 19 displays the hydrogen response of the FBG hydrogen sensor under different relative humidities. When the relative humidity of the air chamber is $32.3 \%$, the wavelength shifts of the FBG hydrogen sensor towards $6000 \mathrm{ppm}, 4400 \mathrm{ppm}$, 3600 ppm, 2800 ppm, 2000 ppm, 1600 ppm, $1200 \mathrm{ppm}, 800 \mathrm{ppm}$, and $400 \mathrm{ppm}$ hydrogen are 298 pm, 210 pm, 152 pm, 110 pm, 86 pm, 56 pm, $44 \mathrm{pm}, 30 \mathrm{pm}$, and $14 \mathrm{pm}$, respectively. When the relative humidity increases to $87.8 \%$, the wavelength shifts of the FBG hydrogen sensor towards $7200 \mathrm{ppm}, 6400 \mathrm{ppm}, 4400 \mathrm{ppm}, 3600 \mathrm{ppm}$, $2800 \mathrm{ppm}, 1600 \mathrm{ppm}, 800 \mathrm{ppm}$, and $400 \mathrm{ppm}$ hydrogen are $404 \mathrm{pm}, 326 \mathrm{pm}, 205 \mathrm{pm}, 148 \mathrm{pm}$, $115 \mathrm{pm}, 57 \mathrm{pm}, 28 \mathrm{pm}$, and $13 \mathrm{pm}$, respectively. Figure 19(c) shows the repeatability response of the FBG hydrogen sensor under different humidities, which demonstrates that the ambient humidities have little effect on its sensitivity when the relative humidity changes from $32.3 \%$ to $87.8 \%$. The FBG hydrogen sensor has the good anti-humidity interference performance due to its porous structure.

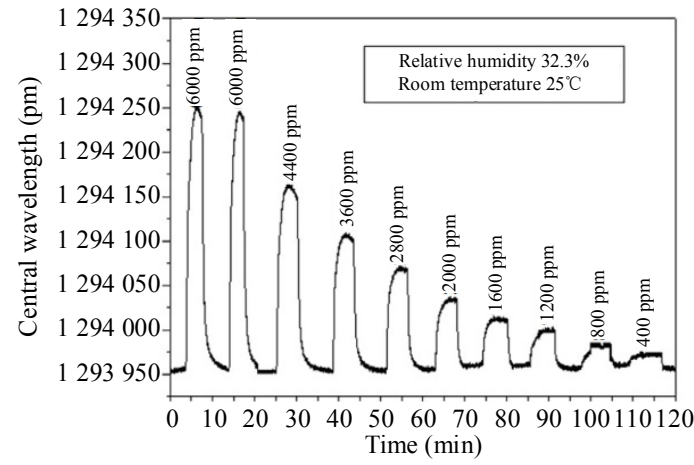

(a)

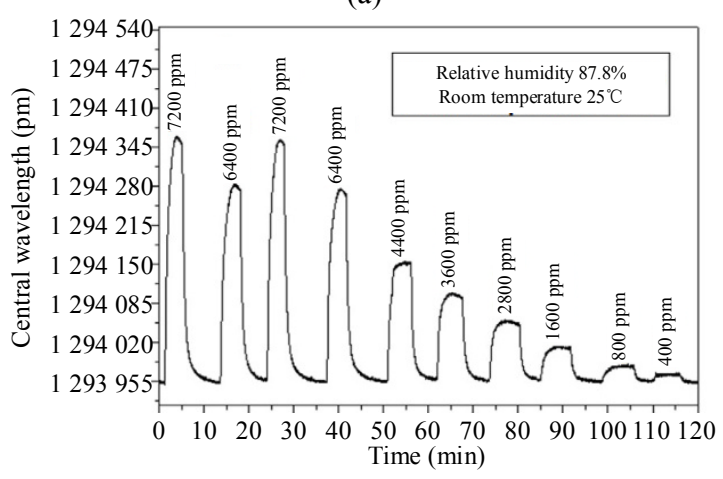

(b)

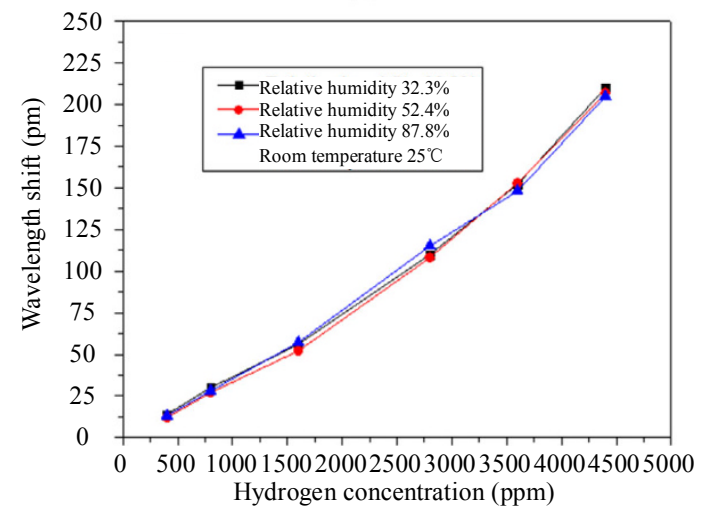

(c)

Fig. 19 Hydrogen response of the FBG coated with Pt-loaded $\mathrm{WO}_{3}$ under different humidities. 
Actually, the performance of the optical hydrogen sensor can be affected by the ambient temperature [55-57] and humidity [58, 59]. Generally, the optical fiber hydrogen sensor has the worse performance at the lower temperature or higher humidity atmosphere. Compared to other optical fiber hydrogen sensors, the FBG hydrogen sensor is more suitable for distributed measurement and easier for temperature compensation due to its wavelength multiplexing capability.

Two types of FBG hydrogen sensors (based on the Pd thin film and Pt-loaded $\mathrm{WO}_{3}$ coating) have been reported, respectively. Table 1 shows the performance comparison of the proposed FBG hydrogen sensor with the two types of FBG hydrogen sensors. The first type of the FBG hydrogen sensor is based on the volume change of $\mathrm{Pd}$ or Pd alloys during the hydrogen response. Silva et al. [60] reported the most sensitive FBG hydrogen sensor based on the Pd thin film. However, FBG hydrogen sensors based on the pure Pd film are easily suffered from Pd film's fatal fracture caused by its $\alpha-\beta$ phase transition. Moreover, Pd can be oxidized by oxygen [61], which has a bad effect on its hydrogen response ability. Another type is based on Pt-loaded $\mathrm{WO}_{3}$ coatings undergoing an exothermic reaction in the hydrogen atmosphere. Compared to Pd-based thin films [62], the Pt-loaded $\mathrm{WO}_{3}$ coating has the better anti-humidity interference. And the FBG hydrogen sensor based on the Pt-loaded $\mathrm{WO}_{3}$ coating has the higher sensitivity and quicker response rate. Although the FBG hydrogen sensor reported by Caucheteur et al. [48] had the better sensitivity and response rate, but its low hydrogen response ability should be improved. And the energy released by the exothermic reaction should be controlled at a proper value so as to ensure its nature safety. The FBG hydrogen sensor proposed in this paper can response to $200 \mathrm{ppm}$ hydrogen at the room temperature of $25{ }^{\circ} \mathrm{C}$, and the temperature increased by the exothermic reaction is much lower than that of the reported work [53]. Nevertheless, the sensing head of the FBG hydrogen sensor is more suitable for the application due to its better encapsulation structure.

Table 1 Comparison of FBG hydrogen sensor.

\begin{tabular}{cccc}
\hline Author, Ref. & $\begin{array}{c}\text { Concentration } \\
\text { range, sensitivity } \\
\left(1 \% \mathrm{H}_{2, \mathrm{v}} / \mathrm{v}\right)\end{array}$ & $\begin{array}{c}\text { Sensing head, } \\
\text { carrying gas }\end{array}$ & $\begin{array}{c}\text { Temperature, } \\
\text { response time }\end{array}$ \\
\hline Silva [60] & $\begin{array}{c}0.1 \%-1 \%, \\
81.8 \mathrm{pm}\end{array}$ & $\begin{array}{c}\text { Tapered FBG, 150 nm } \\
\text { Pd, } \mathrm{N}_{2}\end{array}$ & $\begin{array}{c}\text { Room } \\
\text { temperature, -- }\end{array}$ \\
$\begin{array}{c}0.6 \%-4 \%, \\
\text { Caucheteur [48] } \\
\text { more than 1 nm }\end{array}$ & $\begin{array}{c}\mathrm{FBG}+\mathrm{LFBG} \text { Pt-loaded } \\
\mathrm{WO}_{3} \text { coating, air } \\
\text { Temperature sensitive } \\
\text { Our work }\end{array}$ & $25{ }^{\circ} \mathrm{C}, 4 \mathrm{~s}$ \\
& $\begin{array}{c}\text { FBG, improved } \\
\text { more than } 448 \mathrm{pm}\end{array}$ & $\begin{array}{c}25{ }^{\circ} \mathrm{C}, \\
\text { performance Pt-loaded } \\
\mathrm{WO}_{3} \text { coating, }\end{array}$ & 2 minutes \\
\hline
\end{tabular}

Figure 20 shows the hydrogen response of the FBG hydrogen sensor at different ambient temperatures. Figure 20(a) plots the wavelength shifts of the FBG hydrogen sensor at the ambient temperature of $0{ }^{\circ} \mathrm{C}$. The central wavelength of the FBG decreases from $1293.960 \mathrm{~nm}$ to $1293.542 \mathrm{~nm}$, which is consistent with the product of the temperature sensitivity coefficient and temperature change. When hydrogen concentrations are $6800 \mathrm{ppm}, 6000 \mathrm{ppm}, 5200 \mathrm{ppm}, 4800$ ppm, $4000 \mathrm{ppm}, 3200 \mathrm{ppm}, 2800 \mathrm{ppm}, 2400 \mathrm{ppm}$, $1600 \mathrm{ppm}, 1200 \mathrm{ppm}$, and $400 \mathrm{ppm}$, the wavelength shifts of the FBG are $160 \mathrm{pm}, 125 \mathrm{pm}, 103 \mathrm{pm}$, $80 \mathrm{pm}, 60 \mathrm{pm}, 50 \mathrm{pm}, 39 \mathrm{pm}, 35 \mathrm{pm}, 20 \mathrm{pm}, 13 \mathrm{pm}$, and $4 \mathrm{pm}$, respectively. The experimental results demonstrate that the FBG hydrogen sensor still has certain hydrogen response ability at the low temperature, even at the freezing point.

Figure 20(c) illustrates the wavelength shifts of the FBG hydrogen sensor under the ambient temperature of $11.3{ }^{\circ} \mathrm{C}$. When hydrogen concentrations are $7200 \mathrm{ppm}, 6000 \mathrm{ppm}, 4800 \mathrm{ppm}$, $3600 \mathrm{ppm}, 2800 \mathrm{ppm}, 2400 \mathrm{ppm}, 1200 \mathrm{ppm}, 800 \mathrm{ppm}$, and $400 \mathrm{ppm}$, the wavelength shifts of the FBG are $340 \mathrm{pm}, 267 \mathrm{pm}, 167 \mathrm{pm}, 113 \mathrm{pm}, 87 \mathrm{pm}, 58 \mathrm{pm}, 33 \mathrm{pm}$, $20 \mathrm{pm}$, and $9 \mathrm{pm}$, respectively. Figure 12(e) depicts the wavelength shifts of the FBG hydrogen sensor under the ambient temperature of $29.8{ }^{\circ} \mathrm{C}$. When hydrogen concentrations are $6400 \mathrm{ppm}, 4800 \mathrm{ppm}$, $3600 \mathrm{ppm}, 3200 \mathrm{ppm}, 2800 \mathrm{ppm}, 2400 \mathrm{ppm}, 1600 \mathrm{ppm}$, $1200 \mathrm{ppm}$, and $400 \mathrm{ppm}$, the wavelength shifts of the 
FBG are $350 \mathrm{pm}, 238 \mathrm{pm}, 160 \mathrm{pm}, 141 \mathrm{pm}, 113 \mathrm{pm}$, $99 \mathrm{pm}, 74 \mathrm{pm}, 52 \mathrm{pm}$, and $17 \mathrm{pm}$, respectively. These results show the FBG hydrogen sensor has the better sensitivity at the higher ambient temperature. Since $\mathrm{WO}_{3}$ is a semiconductor material [49], its band gap may be increased at the lower temperature, which has a bad effect on the transmission of $\mathrm{H}^{+}$and $\mathrm{e}^{-}$ during the hydrogen response. Therefore, the energy

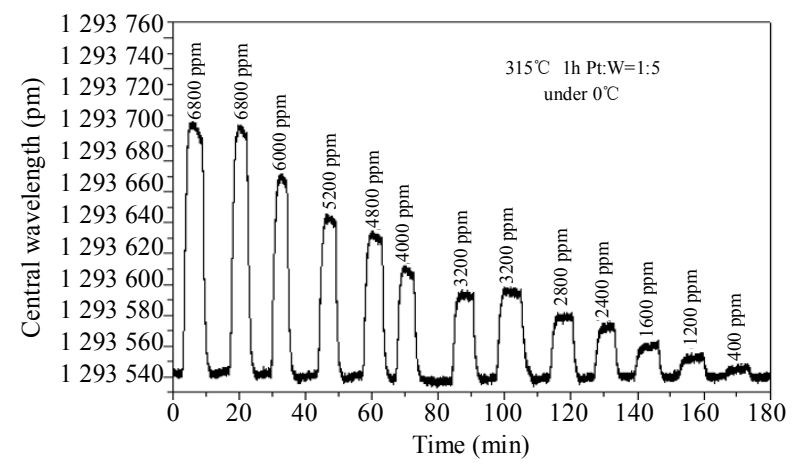

(a)

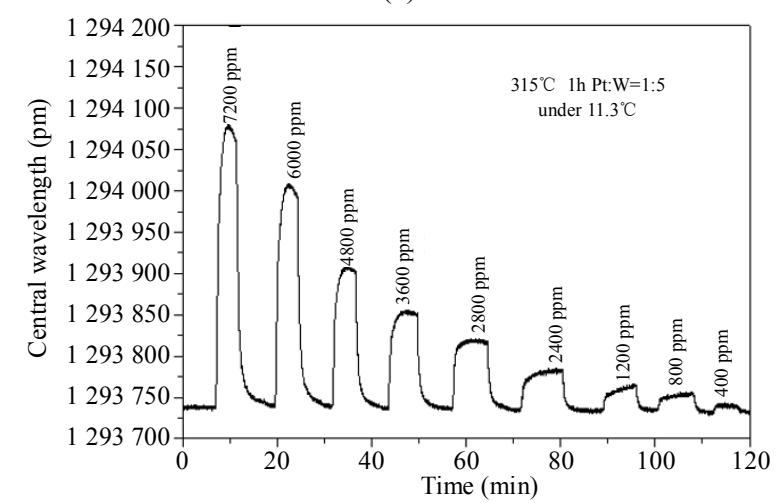

(c)

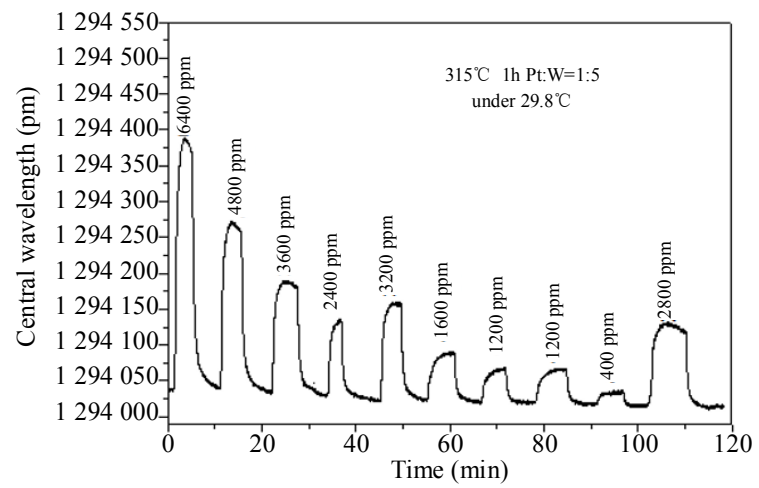

(e) released by exothermic reaction will be reduced, resulting in a decline of the sensitivity of the FBG hydrogen sensor. Although the sensitivity of the FBG hydrogen sensor is influenced by the ambient temperature, its measurement precision can be compensated by using the reference FBG [63]. So it is very important to evaluate the sensitivity variation with the ambient temperature.

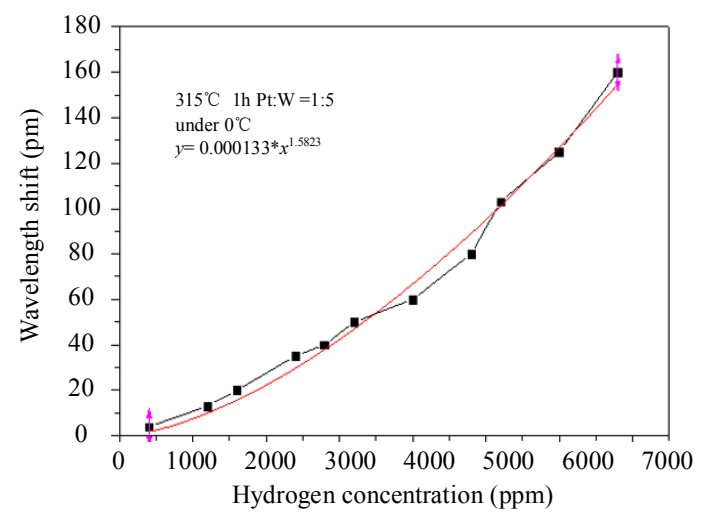

(b)

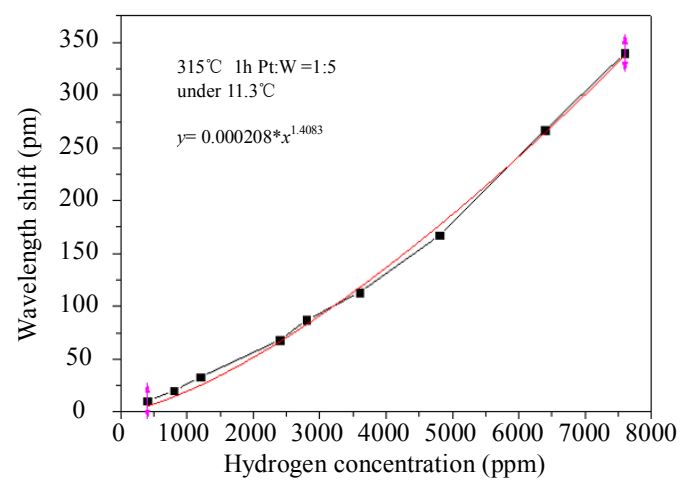

(d)

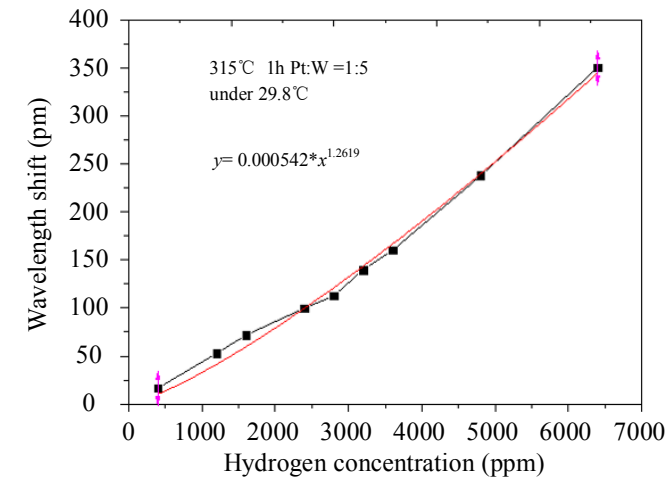

(f)

Fig. 20 Hydrogen response of the FBG coated with the Pt-loaded $\mathrm{WO}_{3}$ coating $(\mathrm{Pt}: \mathrm{W}=1: 5$, one hour thermal treatment under $\left.315{ }^{\circ} \mathrm{C}\right)$ under different ambient temperatures $\left[\left(\right.\right.$ a) $0{ }^{\circ} \mathrm{C}$; (c) $11.3{ }^{\circ} \mathrm{C}$; (e) $\left.29.8{ }^{\circ} \mathrm{C}\right]$ and the fitting of hydrogen response curves $\left[(\mathrm{b}) 0{ }^{\circ} \mathrm{C}\right.$; (d) $11.3{ }^{\circ} \mathrm{C}$; (f) $\left.29.8{ }^{\circ} \mathrm{C}\right]$.

Figures 20(b), 20(d), and 20(f) display the curve $29.8^{\circ} \mathrm{C}$, respectively. The results show that the FBG fitting of the hydrogen response at $0{ }^{\circ} \mathrm{C}, 11.3{ }^{\circ} \mathrm{C}$, and shifts nonlinearly with an increase in hydrogen 
concentrations, which is similar to the curve fitting of the hydrogen response at $25{ }^{\circ} \mathrm{C}$. However, there is more obvious deviation between the curve fitting and actual data at $0{ }^{\circ} \mathrm{C}$. The reason for this phenomenon may be due to the non-uniform temperature field provided by the mixture of ice and water.

As shown in Figs. 20(b), 20(d), and 20(f), the allometric curve $\left(y=A \times x^{B}\right)$ is selected as the fitting curve, in which $y$ is the central wavelength shifts (pm) of the FBG, and $x$ is hydrogen concentration (ppm). From Table 2, it can be concluded that constants $A$ and $B$ of the hydrogen response fitting curve have certain relationship with the ambient temperature.

Table 2 Constants of the hydrogen response curve fitting at different ambient temperatures.

\begin{tabular}{ccc}
\hline Temperature $(\mathrm{K})$ & $A(\mathrm{pm} / \mathrm{ppm})$ & $B$ \\
\hline 273.0 & 0.000133 & 1.5823 \\
284.3 & 0.000208 & 1.4083 \\
298.0 & 0.003000 & 1.3257 \\
302.8 & 0.005420 & 1.2619 \\
\hline
\end{tabular}

As seen in Fig. 21, the constant $A$ increases nonlinearly with an increase in the ambient temperature, while the constant $B$ shows the linearly decreasing trend. As shown in Fig. 21(a), the data fitting equation of the constant $A$ is approximately an exponential function. And the equation fitting of the constants $B$ is shown in Fig. 21(b). By adding the equation of constants $A$ and $B$ in the allometric curve, we can get the relationship between the FBG wavelength shift and hydrogen concentration at different temperatures.

Since the influence of the ambient humidity can be neglected for the proposed FBG hydrogen sensor, the ambient temperature can be measured by using the reference FBG. As expressed in (1), the wavelength shift of the FBG hydrogen sensor is affected by the hydrogen concentration and ambient temperature. Equation (1) provides a theoretical model for the FBG hydrogen sensor, which is helpful for the calibration of such FBG hydrogen sensor, especially for the industrial application.

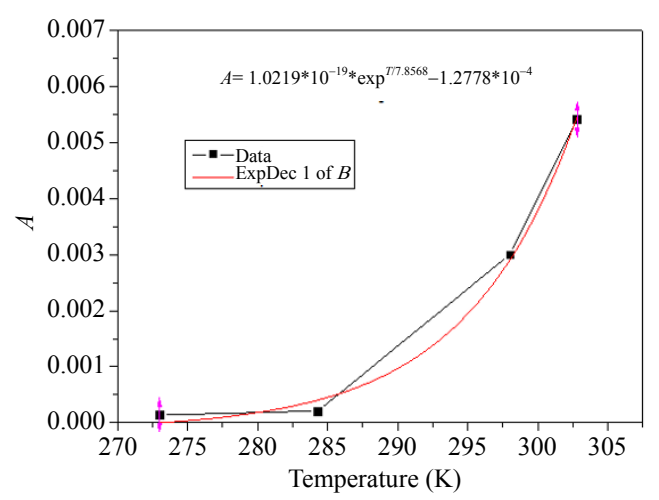

(a)

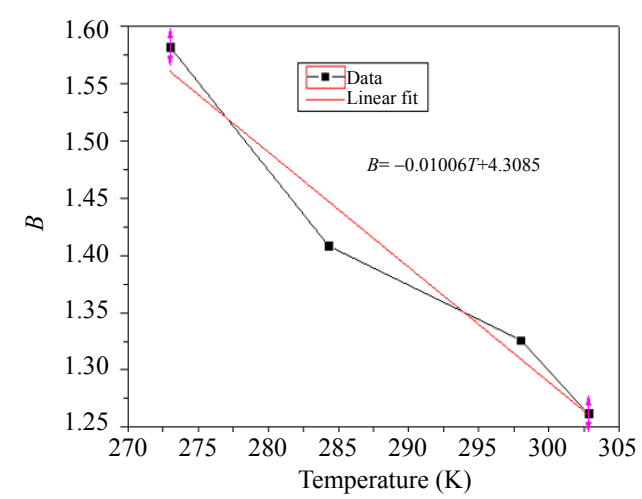

(b)

Fig. 21 Curve fitting $A, B$ with temperature.

The FBG hydrogen sensor based on the Pt-loaded $\mathrm{WO}_{3}$ coating has no response to methane [51] and carbon monoxide [52]. The FBG hydrogen sensor is based on the Pt-loaded $\mathrm{WO}_{3}$ coating undergoing an exothermic reaction in the hydrogen atmosphere, and the sensing probe works at the ambient temperature. A hydrogen molecule can be decomposed into hydrogen atoms by catalyst Pt. Then, the hydrogen atoms penetrate $\mathrm{Pt}$ and react with $\mathrm{WO}_{3}$, generating $\mathrm{H}_{x} \mathrm{WO}_{3}$ [64] or $\mathrm{WO}_{3-x}$ [65]. $\mathrm{H}_{x} \mathrm{WO}_{3}$ or $\mathrm{WO}_{3-x}$ can be oxidized by oxygen to form $\mathrm{WO}_{3}$ in air. Since other reducing gas can not penetrate $\mathrm{Pt}$ catalyst and react with $\mathrm{WO}_{3}$, the Pt-loaded $\mathrm{WO}_{3}$ coating has the good selectivity towards hydrogen at the room temperature. Therefore, the FBG hydrogen sensor based on the Pt-loaded $\mathrm{WO}_{3}$ coating is very promising for hydrogen leakage monitoring in air.

In conclusion, the FBG hydrogen sensor based on the Pt-loaded $\mathrm{WO}_{3}$ coating has been introduced in this paper. The performance of the sensor can be 
greatly improved by combining the Pt-loaded $\mathrm{WO}_{3}$ coating and temperature sensitive FBG. At the room temperature of $25{ }^{\circ} \mathrm{C}$, the $\mathrm{FBG}$ hydrogen sensor has the 448-pm wavelength shift towards $8000 \mathrm{ppm}$ hydrogen, and it can detect hydrogen as low as $200 \mathrm{ppm}$. The performance of the FBG hydrogen sensor was investigated under different ambient humidities and temperatures. The ambient humidity has little effect on the performance of the FBG hydrogen sensor, while the ambient temperature will affect its performance. The FBG hydrogen sensor has the lower sensitivity under the lower ambient temperature. However, the FBG hydrogen sensor still has the 4-pm wavelength shift towards $400 \mathrm{ppm}$ hydrogen, which proves it can detect the low concentration hydrogen at $0{ }^{\circ} \mathrm{C}$.

\section{Intensity-based optical fiber hydrogen sensors}

There are several of hydrogen detection methods dependent on the sensing principle including spectrum modulation and light intensity modulation. The intensity modulation method allows much lower demand for the testing device, which is more suitable for the commercial application. Liu et al. [66] have investigated the reflective fiber hydrogen detection system based on the $\mathrm{Pd} / \mathrm{Y}$ alloy film. This system adopted a dual-path design to eliminate the noise caused by the fluctuations of the light source, fiber loss, and temperature, and therefore improved the signal to noise ratio, which makes it possible to detect the relatively low range of the hydrogen concentration. Typically, such sensor based on the $\mathrm{Pd} / \mathrm{Y}$ alloy film shows very short response time and large response amplitude in the initial few weeks after preparation, but the hydrogen response will become slower after several months due to the oxidation of Y. In this sense, its long-term stability is not good, and the drift of zero-point should be considered in the case of precise measurement. $\mathrm{WO}_{3}$ is a very stable oxide material and exhibits the larger change in its optical properties [67] when it is exposed to hydrogen gas.
A fiber optic hydrogen detection system based on the evaporated amorphous nanostructured $\mathrm{Pt} / \mathrm{WO}_{3}$ films was also proposed and demonstrated. The correlation between the hydrogen concentration and reflective light intensity of the realized sensitive films was investigated and maintained with the dual-path method.

As schematically illustrated in Fig. 22, $\mathrm{WO}_{3}$ thin films were deposited by thermal evaporation on the fused quartz wafer after ultrasonic cleaning for ten minutes. The tungsten boat was filled up with $\mathrm{WO}_{3}$ powder $(99.99 \%)$ at a pressure of $8 \times 10^{-5}$ mbar. To avoid the loss of oxygen atom in the deposited coating, oxygen with a flow velocity of $200 \mathrm{sccm}$ was supplied as process gas during the boat evaporation. The substrate temperature was set at $180{ }^{\circ} \mathrm{C}$, and the depositing speed was $0.15 \AA / \mathrm{s}$. The $\mathrm{WO}_{3}$ coating thickness was $80 \mathrm{~nm}$ monitored by the quartz crystal method. Then, $3.5 \mathrm{~nm} \mathrm{Pt}$ was sputtered on the surface of the $\mathrm{WO}_{3}$ film in $\mathrm{Ar}$ atmosphere $\left(5 \times 10^{-3}\right.$ mbar $)$ with the BESTECH sputtering system.

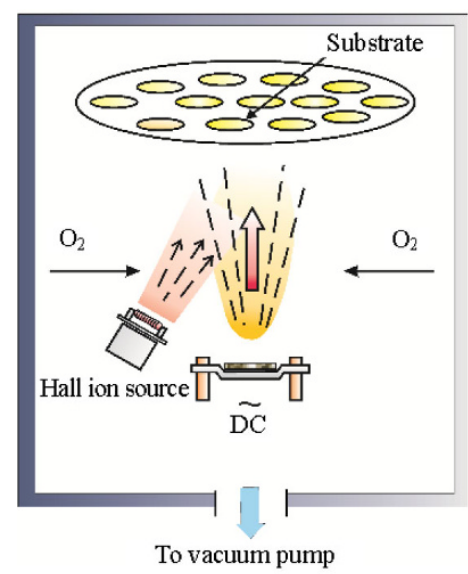

Fig. 22 Schematic of $\mathrm{WO}_{3}$ film deposition with thermal evaporation.

The $\mathrm{Pt} / \mathrm{WO}_{3}$ film X-ray diffraction pattern was obtained on an X-ray diffractometer (XRD D8 Advance, Brucker, German) using the $\mathrm{Cu} \mathrm{Ka}$ radiation source operating at $40 \mathrm{kV}$ and $30 \mathrm{~mA}$ with a scanning speed of $2^{\circ}$ per minute. The film thickness was confirmed by an ellipsometer (WVASE32, J. A. Woollam Co., Inc.). To conduct a deeper research on the influence of hydrogen cycles 
on the $\mathrm{Pt} / \mathrm{WO}_{3}$ film, the morphology was examined by a field emission scanning electron microscope (FE-SEM ULTRA PLUS-43-13, Zeiss, Germany) before and after hydrogen tests.

The $\mathrm{WO}_{3}$ film would be colored in dark blue when exposed to hydrogen gas in the presence of catalyst like Pt. Meanwhile, the refractive index $(n)$ of the $\mathrm{WO}_{3}$ film would decrease rapidly especially in the range of the visible spectrum, and the absorption coefficient $(k)$ would increase accordingly. As a result, the reflective intensity of the $\mathrm{Pt} / \mathrm{WO}_{3}$ film decreased greatly. It is worthy to note that the $3.5 \mathrm{~nm}$ Pt film acting as the catalyst has little influence on the modulation of the reflective intensity when exposed to hydrogen gas. The bleaching process works in the opposite way. A reflective fiber hydrogen testing system was designed to investigate the correlation between the reflective intensity and hydrogen concentration. Figure 23 is the schematic diagram of the experimental system. A home-made optical fiber bundle was realized to transmit light from the light-emitting diode (LED) source to the sensitive films which were deposited on quartz glasses. In this way, the reflected light would be detected simultaneously. Photoelectric detectors connected to the optical fiber bundle were used to detect the reflective intensity. Two different signals called reference signal $\left(I_{r}\right)$ and hydrogen signal $\left(I_{h}\right)$, would be obtained by photoelectric detectors after processed with the NI data acquisition card (USB 9125). The hydrogen sensing measurements were conducted using the standard $\mathrm{H}_{2} / \mathrm{N}_{2}$ gaseous mixture (4\%, $1 \%, 0.5 \%, 0.1 \%$, and $0.05 \%)$. When the hydrogen signal is stable, the hydrogen supply can be turned off to enable the recovery of the sensor. The process of response and recovery is called one hydrogen cycle. The reference signal obtained from another sample in a sealed chamber was not influenced by the hydrogen concentration, and it would be used to eliminate the noise effect caused by light source fluctuation, fiber loss fluctuation, and temperature. Finally, the noise-compensated output signal can be expressed as follows:

$$
S_{\text {out }}=\mathrm{a} \frac{I_{r}}{I_{h}}+\mathrm{b}
$$

where $\mathrm{a}$ and $\mathrm{b}$ are constants, and $S_{\text {out }}$ is a nondimensional parameter and the function of hydrogen concentration.

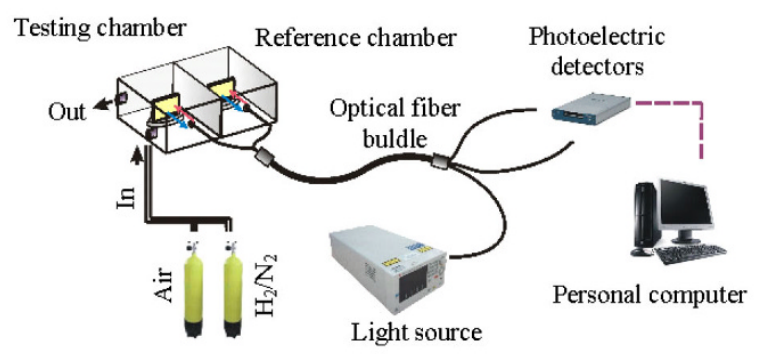

Fig. 23 Configuration of the hydrogen sensing experiment.

The surface topology and micro-structure of the $\mathrm{WO}_{3}$ film are rather important for hydrogen sensing performance. The micro-structure and film morphology of the deposited $\mathrm{WO}_{3}$ film by vacuum thermal evaporation were examined in this work. The XRD pattern of $\mathrm{WO}_{3}$ shows that the as-deposited film has an amorphous structure with no obvious XRD peaks but a broad hump near $2 \theta=$ $25^{\circ}$. Compared to the crystalline state with the dense surface and structure, the amorphous structure [68, 69] tends to be loose, which is beneficial to the diffusion of hydrogen molecules, and therefore is helpful to the coloring or bleaching process during hydrogen reaction. Figure 24 shows the FE-SEM image of the $\mathrm{Pt} / \mathrm{WO}_{3}$ film after 200 times of the hydrogen cycle. There is little difference between films before and after hydrogen cycles. The adhesion between the film and substrate is still excellent compared to that before hydrogen cycles.

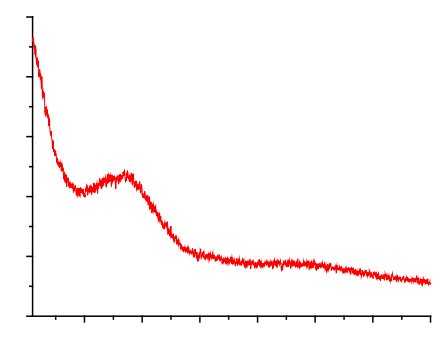

Fig. 24 XRD pattern of the $\mathrm{WO}_{3}$ film. 
Intensive investigations have been conducted on optical characteristics of $\mathrm{WO}_{3}$ coatings under different hydrogen concentrations [70, 71], mainly these works are focused on the study of the absorption or transmission spectrum when the $\mathrm{WO}_{3}$ coating is exposed to hydrogen gas. Different from those reported work, we tried to find the correlation of the reflective intensity and hydrogen concentrations, especially in the lower range (less than $5000 \mathrm{ppm}$ ). Figure 25 depicts the hydrogen response of the $\mathrm{Pt} / \mathrm{WO}_{3}$ film under different concentrations $(0.05 \%, 0.1 \%, 0.5 \%, 1 \%$, and $4 \%)$, and the response values of sensors are $86.8 \mathrm{mV}$, $75 \mathrm{mV}, 67.6 \mathrm{mV}, 53.2 \mathrm{mV}$, and $48.3 \mathrm{mV}$, respectively. Firstly, it can be found that the response curve is clearly smooth because of the high signal to noise ratio which is mainly dependent on the sensitive properties of films to hydrogen exposure. There are obviously different responses when exposed to different hydrogen concentrations, which demonstrates a better performance compared with the noble Pd metal or alloy films [72]. The response value is still $48.3 \mathrm{mV}$ in the 500 -ppm hydrogen concentration, which is nearly half of that in $40000 \mathrm{ppm}$. The resolution of this type of sensor for hydrogen gas becomes much higher in the lower range hydrogen concentration. Secondly, owing to a porous amorphous structure of the $\mathrm{WO}_{3}$ coating and the thin sputtered Pt film as the catalyst, the response time is very short $(10 \mathrm{~s}-60 \mathrm{~s})$ when exposed to $4 \% \mathrm{H}_{2}, 1 \% \mathrm{H}_{2}$, and $0.5 \% \mathrm{H}_{2}$, and it nearly takes no time (in several seconds) to recover in flowing air. However, longer response and recovery time was observed with a decrease in the hydrogen concentration in the lower range $(0-5000 \mathrm{ppm})$. In contrast, noble Pd metal or alloy films are easily insensitive, especially after several hydrogen cycles $[73,74]$. The $\mathrm{Pt} / \mathrm{WO}_{3}$ film can still preserve a high coloring or bleaching velocity after undergoing several cycles or months.

Hydrogen cycle experiments were also conducted in order to investigate the repeatability and stability of the fiber optic hydrogen sensors with the evaporated $\mathrm{WO}_{3} / \mathrm{Pd}$ film. As shown in Fig. 26, the sensing repeatability and stability are quite promising for applications.

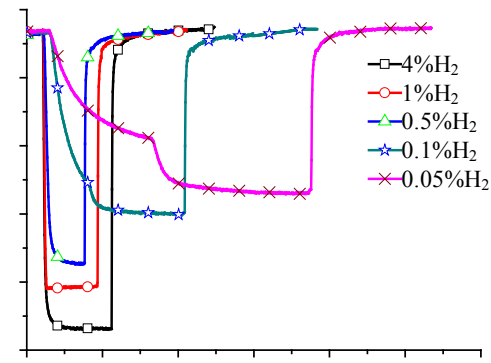

Fig. 25 Response curve in $4 \% \mathrm{H}_{2}, 1 \% \mathrm{H}_{2}, 0.5 \% \mathrm{H}_{2}, 1 \% \mathrm{H}_{2}$, and $0.05 \% \mathrm{H}_{2}$.

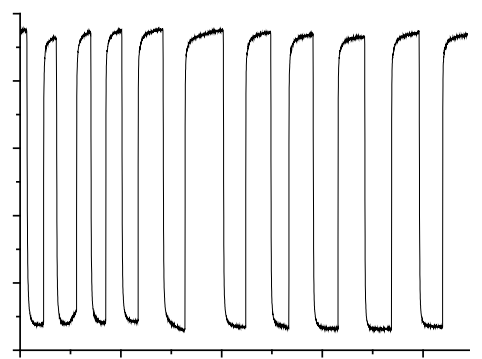

Fig. 26 Ten loading / unloading cycles response of the hydrogen sensor in $4 \% \mathrm{H}_{2}$.

Figure 27 plots the curve fitting of the response value of the sensor under different hydrogen concentrations. As shown in Fig. 27, the response value of the sensor increases nonlinearly with an increase in the hydrogen concentration. Since the whole tests were conducted in an environment under the normal pressure, low noise, and room temperature, the fluctuation of the reference signal

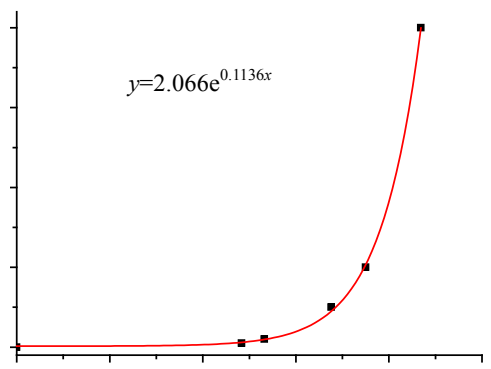

Fig. 27 Curve fitting response value of the hydrogen sensor under different concentrations $\left(0.05 \% \mathrm{H}_{2}, 0.1 \% \mathrm{H}_{2}, 0.5 \% \mathrm{H}_{2}\right.$, $1 \% \mathrm{H}_{2}$, and $4 \% \mathrm{H}_{2}$ ). 
was no more than $3 \mathrm{mV}$ which was further less than that of the hydrogen signals. It can be concluded from Fig. 27 that the resolution in the low range $(0-$ $0.5 \%$ ) hydrogen concentration is larger than that in the high range $(0.5 \%-4 \%)$. It is promising for such sensor to be employed in the relatively low range hydrogen concentration sensing and detection.

A fiber optic hydrogen sensor based on the evaporated $\mathrm{Pt} / \mathrm{WO}_{3}$ film was proposed and experimentally demonstrated. The amorphous structured $\mathrm{WO}_{3}$ film was successfully prepared by vacuum thermal evaporation, as the catalyst a 3.5-nm Pt film was sputtered on the $\mathrm{WO}_{3}$ film to improve its sensitivity to hydrogen response. In this work, the sensing performances including the response value, colouring or bleaching velocity, repeatability, and reliability under different hydrogen concentrations were investigated. Hydrogen sensing results showed that the reflective intensity would decrease with an increase in the hydrogen concentration. The response values of the sensor can reach to $86.8 \mathrm{mV}, 75 \mathrm{mV}, 67.6 \mathrm{mV}$, $53.2 \mathrm{mV}$, and $48.3 \mathrm{mV}$ under $4 \% \mathrm{H}_{2}, 1 \% \mathrm{H}_{2}, 0.5 \% \mathrm{H}_{2}$, $0.1 \% \mathrm{H}_{2}$, and $0.05 \% \mathrm{H}_{2}$, respectively and increase nonlinearly with an increase in the hydrogen concentration. Response and recovery time was rather short $(10 \mathrm{~s}-60 \mathrm{~s})$ when the sensor was exposed to the high range hydrogen concentration $(0.5 \%-4 \%)$. Although the response speed would slow down to some extent when the hydrogen concentration was below $0.5 \%$, the response value was still more than half of that in $4 \% \mathrm{H}_{2}$. The sensitivity in the low range hydrogen concentration was much higher than that in the high range. Repeated experiments and FE-SEM images show that the $\mathrm{Pt} / \mathrm{WO}_{3}$ film is stable without any crack or delamination effect after hydrogen cycles, which demonstrates a good repeatability and reliability of the proposed sensor and hydrogen detection system.

\section{Conclusions}

Palladium has been intensively investigated due to its obvious optical constant alternation when exposed to hydrogen, however this metal film is susceptible to mechanical damage such as cracking, blistering, and delamination caused by the phase transition in the process of repeated absorption and desorption of hydrogen. This so-called embrittlement effect has negative consequences for the stability of hydrogen sensors based on these noble metals. Doping some other metals including $\mathrm{Ni}$ [73], $\mathrm{Au}$ [74], and Y [76] in the pure palladium can suppress this phase transition and therefore deduce the embrittlement effect to some extent, but the sensitivity and accuracy of these sensitive films will decrease with the improved mechanical stability. Tungsten oxide $\left(\mathrm{WO}_{3}\right)$ is a transition metal oxide with the wide bandgap from $E_{g}=2.60 \mathrm{eV}$ to $3.25 \mathrm{eV}$ and perovskite-like atomic configurations based on corner-sharing $\mathrm{WO}_{6}$ octahedra. The optical properties (reflectance or transmittance) of $\mathrm{WO}_{3}$ in the visible region can be modulated, and the reversible and persistent changes in optical constants including refractive index and absorption resulting from the external stimuli make it an ideal candidate for hydrogen detection. To improve the sensitivity of the film to hydrogen, a thin coating of the catalyst which can dissociate the hydrogen molecule into atoms and therefore decrease the reaction activation energy, like $\mathrm{Pt}$, is often sputtered on the $\mathrm{WO}_{3}$ film to facilitate absorption and desorption of hydrogen [75]. Moreover, the $\mathrm{WO}_{3}$ film in the nanostructure appears to be more sensitive to hydrogen especially for the relatively low hydrogen concentration (down to $1000 \mathrm{ppm}$ ), due to its large surface to volume ratio [76]. Nanostructured $\mathrm{WO}_{3}$ [77] including nanopartical, nano-rod, nano-wire, nano-platelet or even nano-tree can be prepared through various deposition techniques such as the thermal evaporation, hydrothermal method, e-beam, sputtering, and sol-gel coating. The growth of the $\mathrm{WO}_{3}$ coating can be controlled and optimized with experimental preparation parameters such as the temperature, process gas atmosphere, and annealing treatment. 


\section{Acknowledgments}

This work is finically supported by the project of the National Science Foundation of China, NSFC (Number: 60908020, 61290311) and program for the New Century Excellent Talents in University (NCET-10-0664).

Open Access This article is distributed under the terms of the Creative Commons Attribution License which permits any use, distribution, and reproduction in any medium, provided the original author(s) and source are credited.

\section{References}

[1]M. Tabib-Azar, B. Sutapun, R. Petrick, and A. Kazemi, "Highly sensitive hydrogen sensors using palladium coated fiber optics with exposed cores and evanescent field interactions," Sensors and Actuators B: Chemical, 1999, 56(1-2): 158-163.

[2] S. K. Khijwania and B. D. Gupta, "Fiber optic evanescent field absorption sensor: effect of fiber parameters and geometry of the probe," Optical and Quantum Electronics, 1999, 31(8): 625-636.

[3] S. Sekimoto, H. Nakagawa, S. Okazaki, K. Fukuda, S. Asakura, T. Shigemori, et al., "A fiber-optic evanescent-wave hydrogen gas sensor using palladium-supported tungsten oxide," Sensors and Actuators B: Chemical, 2000, 66(1-3): 142-145.

[4] J. Villatoro and D. Monzón-Hernándea, "Fast detection of hydrogen with nano fiber tapers coated with ultra thin palladium layers," Optics Express, 2005, 13(13): 5087-5092.

[5] D. Monzón-Hernández, D. Luna-Moreno, and D. Martínez-Escobar, "Fast response fiber optic hydrogen sensor based on palladium and gold nano-layers," Sensors and Actuators B: Chemical, 2009, 136(2): 562-566.

[6] M. Yang, H. Liu, D. Zhang, and X. Tong, "Hydrogen sensing performance comparison of Pd layer and $\mathrm{Pd} / \mathrm{WO}_{3}$ thin film coated on side-polished single- and multi-mode fibers," Sensors and Actuators B: Chemical, 2010, 149(1): 161-164.

[7] M. Yang, Y. Sun, D. Zhang, and D. Jiang, "Using $\mathrm{Pd} / \mathrm{WO}_{3}$ composite thin films as sensing materials for optical fiber hydrogen sensors," Sensors and Actuators B: Chemical, 2010, 143(2): 750-753.

[8] M. A. Butler, "Micromirror optical-fiber hydrogen sensor," Sensors and Actuators B: Chemical, 1994, 22(2): 155-163.

[9] X. B évenot, A. Trouillet, C. Veillas, H. Gagnaire, and M. Clément, "Hydrogen leak detection using an optical fibre sensor for aerospace applications," Sensors and Actuators B: Chemical, 2000, 67(1-2): 57-67.
[10] K. Lin, Y. Lu, J. Chen, R. Zheng, P. Wang, and H. Ming, "Surface plasmon resonance hydrogen sensor based on metallic grating with high sensitivity," Optics Express, 2008, 16(23): 18599-18604.

[11] C. Ma and A. Wang, "Optical fiber tip acoustic resonator for hydrogen sensing," Optics Letters, 2010, 35(12): 2043-2045.

[12] M. Buric, T. Chen, M. Maklad, P. R. Swinehart, and K. P. Chen, "Multiplexable low-temperature fiber Bragg grating hydrogen sensors," IEEE Photonics Technology Letters, 2009, 21(21): 1594-1596.

[13] M. Buric, K. P. Chen, M. Bhattarai, P. R. Swinehart, and M. Maklad, "Active fibre Bragg grating hydrogen sensor for all-temperature operation," IEEE Photonics Technology Letters, 2007, 19(5): 255-257.

[14] B. Sutapun, M. Tabib-Azar, and A. Kazemi, "Pd-coated elastooptic fiber optic Bragg grating sensors for multiplexed hydrogen sensing," Sensors and Actuators B: Chemical, 1999, 60(1): 27-34.

[15] C. Caucheteur, M. Debliquy, D. Lahem, and P. Mégret, "Hybrid fiber gratings coated with a catalytic sensitive layer for hydrogen sensing in air," Optics Express, 2008, 16(21): 16854-16859.

[16] J. Dai, M. Yang, Y. Chen, K. Cao, H. Liao, and P. Zhang, "Side-polished fiber Bragg grating sensor with $\mathrm{WO}_{3}$-Pd composite film as sensing materials," Optics Express, 2011, 19(7): 6141-6148.

[17] J. H. Lee, J. H. Kim, Y. G. Han, S. H. Kim, and S. B. Lee, "Investigation of Raman fiber laser temperature probe based on fiber Bragg gratings for long-distance remote sensing applications," Optics Express, 2004, 12(8): 1747-1752.

[18] G. T. Kanellos, G. Papaioannou, D. Tsiokos, C. Mitrogiannics, G. Nianios, and N. Pleros, "Two dimensional polymer-embedded quasidistributed FBG pressure sensor for biomedical applications," Optics Express, 2010, 18(1): 179-186.

[19] D. Lin, X. Jiang, F. Xie, W. Zhang, Z. Lin, and I. Bennion, "High stability multiplexed fibre interferometer and its application on absolute displacement measurement and on-line surface metrology," Optics Express, 2004, 12(23): 5729-5734.

[20] M. Armgarth and C. Nylander, "Blister formation in Pd gate MIS hydrogen sensors," IEEE Electron Device Letters, 1982, 3(12): 384-386.

[21] B. McCool, G. Xomeritakis, and Y. S. Lin, "Composition control and hydrogen permeation characteristics of sputter deposited palladium-silver membranes," Journal of Membrane Science, 1999, 161(1-2): 67-76.

[22] J. Shu, A. Adnot, B. P. A. Grandjean, and S. Kaliaguine, "Structurally stable composite $\mathrm{Pd}-\mathrm{Ag}$ alloy membranes: introduction of a diffusion barrier," Thin Solid Films, 1996, 286(1-2): 72-79.

[23] S. Uemiya, T. Matsuda, and E. Kikuchi, "Hydrogen permeable palladium-silver alloy membrane supported on porous ceramics," Journal of Membrane Science, 1991, 56(3): 315-325. 
[24] A. D. Kersey, M. A. Davis, H. J. Patrick, M. LeBlac, K. P. Koo, C. G. Askins, et al., "Fiber grating sensors," Journal of Lightwave Technology, 1997, 15(8): 1442-1463.

[25] K. O. Hill, B. Malo, F. Bilodeau, D. C. Johnson, and J. Albert, "Bragg gratings using fabricated in monomode photosensitive optical fiber by UV exposure thorough a phase mask," Applied Physics Letters, 1993, 62(10): 1035-1037.

[26] K. S. Chiang, R. Kancheti, and V. Rastogi, "Temperature-compensated fiber-Bragg-gratings for DC and AC currents," Optical Engineering, 2003, 42(7): 1906-1909.

[27] M. Yang, J. Dai, C. Zhou, and D. Jiang, "Optical fiber magnetic field sensors with TbDyFe magnetostrictive thin films as sensing materials," Optics Express, 2009, 17(23): 20777-20782.

[28] Z. Zhao, M. Knight, S. Kumar, E. T. Eisenbraun, and M. A. Carpenter, "Humidity effects on Pd/Au-based all-optical hydrogen sensors," Sensors and Actuators B: Chemical, 2008, 129(2): 726-733.

[29] M. Wang and Y. Feng, "Palladium-silver thin film for hydrogen sensing," Sensors and Actuators B: Chemical, 2001, 123(1): 101-106.

[30] Y. K. Gautam, A. K. Chawla, S. A. Khan, R. D. Agrawal, and R. Chandra, "Hydrogen sbsorption and optical propeties of $\mathrm{Pd} / \mathrm{Mg}$ thin films prapared by DC magnetron sputtering," International Journal of Hydrogen Energy, 2012, 37(4): 3772-3778.

[31]R. Kumar, D. Varadani, B. R. Mehta, V. N. Singh, Z. Wen, X. Feng, et al., "Fast response and recovery of hydrogen sensing in Pd-Pt nanoparticle-graphene composite layers," Nanotechnology, 2011, 22(27): 275719-1-275719-7.

[32] Z. Zhao, M. Knight, S. Kumar, E. T. Eisenbraun, and M. A. Carpenter, "Humidity effects on Pd/Au-based all-optical hydrogen sensors," Sensors and Actuators B: Chemical, 2008, 129(2): 726-733.

[33] E. Lee, J. M. Lee, E. Lee, J. S. Noh, J. H. Joe, B. Jung, et al., "Hydrogen gas sensing performance of Pd-Ni alloy thin films," Thin Solid Films, 2010, 519(2): 880-884.

[34] M. Yang, J. Dai, C. Zhou, and D. Jiang, "Optical fiber magnetic field sensors with TbDyFe magnetostrictive thin film as sensing materials," Optics Express, 2009, 17(23): 20777-20782.

[35] D. Luna-Moreno, D. Monzon-Hernandez, S. Calixto-Carrera, and R. Espinosa-Luna, "Tailored $\mathrm{Pd}-\mathrm{Au}$ layer produced by conventional evaporation process for hydrogen sensing," Optics and Lasers in Engineering, 2011, 49(6): 693-697.

[36] J. Y. Shim, J. D. Lee, J. M. Jin, H. Cheong, and S. Lee, "Pd-Pt alloy as a catalyst in gasochromic thin films for hydrogen sensors," Solar Energy Materials and Solar Cells, 2009, 93(12): 2133-2137.

[37] J. Dai, M. Yang, X. Yu, K. Cao, and J. Liao, "Greatly etched fiber Bragg grating hydrogen sensor with $\mathrm{Pd} / \mathrm{Ni}$ composite film as sensing material," Sensors and Actuators B: Chemical, 2012, 174: 253-257.
[38]A. Iadicicco, A. Cutolo, R. Bernini, and M. Giordano, "Thinned fiber Bragg gratings as high sensitivity refractive index sensor," IEEE Photonics Technology Letters, 2004, 16(4): 1149-1151.

[39] J. Dai, M. Yang, X. Yu, and H. Lu, "Optical hydrogen sensor based on etched FBG sputtered with $\mathrm{Pd} / \mathrm{Ag}$ composite film," Optical Fiber Technology, 2013, 19(1): 26-30.

[40] B. Sutapun, M. Tabib-Azar, and A. Kazemi, "Pd-coated elastooptic fiber optic Bragg grating sensors for multiplexed hydrogen sensing," Sensors and Actuators B: Chemical, 1999, 60(1,2): 27-34.

[41] Y. Cheng, Y. Li, D. Lisi, and W. M. Wang, "Preparation and characterization of $\mathrm{Pd} / \mathrm{Ni}$ thin films for hydrogen sensing," Sensors and Actuators B: Chemical, 1996, 30(1): 11-16.

[42] K. Scharnagl, M. Efiksson, A. Karthigeyan, M. Burgmair, M. Zimmer, and I. Eisele, "Hydrogen detection at high concentrations with stabilished palladium," Sensors and Actuators B: Chemical, 2001, 78(1-3): 138-142.

[43] D. Luna-Moreno, D. Monzon-Hernandez, S. Calixto-Carrera, and R. Espinosa-Luna, "Tailored $\mathrm{Pd}-\mathrm{Au}$ layer produced by conventional evaporation process for hydrogen sensing," Optics and Lasers in Engineering, 2011, 49(6): 693-697.

[44] G. Rajan, M. Y. M. Noor, N. H. Lovell, E. Ambikaizrajah, G. Farrell, and G. D. Peng, "Polymer micro-fiber Bragg grating," Optics Letters, 2013, 38(17): 3359-3362.

[45] A. Lebon, A. García-Fuente, A. Vega, and F. Aguilera-Granja, "Hydrogen interaction in Pd-Pt alloy nanoparticles," Journal of Physical Chemistry $C, 2012,116(1): 126-133$.

[46] Wei He, Juanying Liu, Xiaogang Zhang, Daniel L. Akins, Hui Yang, "Simple preparation of PdPt nanoalloy catalysts for methanol-tolerant oxygen reduction", J. Power Sources, 2010, 195 1046-1050.

[47] J. Y. Shi m, J. D. Lee, J. M. Jin, H. Cheong, and S. Lee, "Pd-Pt alloy as a catalyst in gasochromic thin films for hydrogen sensors," Solar Energy Materials and Solar Cells, 2009, 93(12): 2133-2137.

[48] C. Caucheteur, M. Debliquy, D. Lahem, and P. Mégret, "Hybrid fiber gratings coated with a catalytic sensitive layer for hydrogen sensing in air," Optics Express, 2008, 16(21): 16854-16859.

[49] M. Zhao and C. W. Ong, "Improved $\mathrm{H}_{2}$-sensing performance of nanocluster-based highly porous tungsten oxide films operating at moderate temperature," Sensors and Actuators B: Chemical, 2012, 174: 65-73.

[50] A. Boudiba, C. Zhang, P. Umek, C. Bittencourt, R. Snyders, M. G. Olivier, et al., "Sensitive and rapid hydrogen sensors based on $\mathrm{Pd}-\mathrm{WO}_{3}$ thick films with different morphologies," International Journal of Hydrogen Energy, 2013, 38(5): 2565-2577.

[51] C. Caucheteur, M. Debliquy, D. Lahem, and P. Mégret, "Hydrogen sensor using fiber gratings covered by a catalytic sensitive layer," in Proc. SPIE, 
vol. 6593, pp. 65930U, 2007.

[52] M. Yang, Z. Li, J. Dai, Z. Yang, Y. Zhang, and Z. Zhuang, "Comparison of optical fiber Bragg grating hydrogen sensors with Pd-based thin films and sol-gel $\mathrm{WO}_{3}$ coatings," Measurement Science and Technology, 2013, 24(9): 094009.

[53] C. Caucheteur, M. Debliquy, D. Lahem, and P. Mégret, "Catalytic fiber Bragg grating sensor for hydrogen leak detection in air," IEEE Photonics Technology Letters, 2008, 20: 96-98.

[54] M. Yang, Z. Yang, J. Dai, and D. Zhang, "Fiber optic hydrogen sensors with sol-gel $\mathrm{WO}_{3}$ coatings," Sensors and Actuators B: Chemical, 2012, 166-167: 632-636.

[55] M. Buric, K. P. Chen, M. Bhattarai, P. R. Swinehart, and M. Maklad, "Active fiber Bragg grating hydrogen sensors for all-temperature operation," IEEE Photonics Technology Letters, 2007, 19(5): 255-257.

[56] M. Buric, T. Chen, M. Maklad, P. R. Swinehart, and K. P. Chen, "Multiplexable low-temperature fiber Bragg grating hydrogen sensors," IEEE Photonics Technology Letters, 2009, 21(21): 1594-1596.

[57] J. Z. Ou, M. H. Yaacob, J. L. Campbell, M. Breedon, K. Kalantar-zadeh, and W. Wlodarski, " $\mathrm{H}_{2}$ sensing performance of optical fiber coated with nano-platelet $\mathrm{WO}_{3}$ film," Sensors and Actuators B: Chemical, 2012, 166-167: 1-6.

[58] Z. Zhao, M. Knight, S. Kumar, E. T. Eisenbraun, and M. A. Carpenter, "Humidity effects on Pd/Au-based all-optical hydrogen sensors," Sensors and Actuators B: Chemical, 2008, 129(2): 726-733.

[59] R. J. Westerwaal, J. S. A. Rooijmans, L. Leclercq, D. G. Gheorghe, T. Radeva, L. Mooij, et al., "Nanostructured Pd-Au based fiber optic sensors for probing hydrogen concentrations in gas mixtures," International Journal of Hydrogen Energy, 2013, 38(10): 4201-4212.

[60] S. Silva, L. Coelho, J. M. Almeida, O. Frazão, J. L. Santos, F. X. Malcata, et al., " $\mathrm{H}_{2}$ sensing based on a Pd-coated tapered-FBG fabricated by DUV femtosecond laser technique," IEEE Photonics Technology Letters, 2013, 25(4): 401-403.

[61] M. Aleixandre, P. Corredera, M. L. Hernanz, and J. Gutierrez-Monreal, "Development of fiber optic hydrogen sensors for testing nuclear waste repositories," Sensors and Actuators B: Chemical, 2005, 107(1): 113-120.

[62] S. F. Silva, L. Coelho, O. Frazão, J. L. Santos, and F. X. Malcata, "A review of palladium-based fiberoptic sensors for molecular hydrogen detection," IEEE Sensors Journal, 2012, 12(1): 93-102.

[63] J. Dai, M. Yang, Y. Chen, K. Cao, H. Liao, and P. Zhang, "Side-polished fiber Bragg grating hydrogen sensor with $\mathrm{WO}_{3}-\mathrm{Pd}$ composite film as sensing materials," Optics Express, 2011, 19(7): 6141-6148.

[64] C. Chan, W. C. Hsu, C. C. Chang, and C. S. Hsu, "Hydrogen incorporation in gasochromic coloration of sol-gel $\mathrm{WO}_{3}$ thin films," Sensors and Actuators B:
Chemical, 2011, 157(2): 504-509.

[65] L. F. Zhu, J. C. She, J. Y. Luo, S. Z. Deng, J. Chen, X. W. Ji, et al., "Self-heated hydrogen gas sensors based on Pt-coated $\mathrm{W}_{18} \mathrm{O}_{49}$ nanowire networks with high sensitivity, good selectivity and low power consumption," Sensors and Actuators B: Chemical, 2011, 153(2): 354-360.

[66] Y. Liu, Y. Chen, H. Song, and G. Zhang, "Modeling analysis and experimental study on the optical fiber hydrogen sensor based on Pd-Y alloy thin film," Review of Scientific Instruments, 2012, 83(7): 075001.

[67] R. Ghosh, M. B. Baker, and R. Lopez., "Optical properties and aging of gasochromic $\mathrm{WO}_{3}$," Thin Solid Films, 2010, 518(8): 2247-2249.

[68] C. Chan, W. Hsu, C. Chang, and C. Hsu, "Hydrogen incorporation in gasochromic coloration of sol-gel $\mathrm{WO}_{3}$ thin films," Sensors and Actuators B: Chemical, 2011, 157(2): 504-509.

[69] A. Boudiba, C. Zhang, and P. Umek, "Sensitive and rapid hydrogen sensors based on $\mathrm{Pd} / \mathrm{WO}_{3}$ thick films with different morphologies," International Journal of Hydrogen Energy, 2013, 38(5): 2565-2577.

[70] M. H. Yaacob, M. Breedon, K. Kalantar-Zadeh, and W. Wlodarski, "Absorption spectral response of nanotextured $\mathrm{WO}_{3}$ thin films with $\mathrm{Pt}$ catalyst towards $\mathrm{H}_{2}$," Sensors and Actuators B: Chemical, 2009, 137(1): 115-120.

[71] M. H. Yaacob, M. Z. Ahmad, A. Z. Sadek, J. Z. Oub, J. Campbell, K. Kalantar-zadeh, et al., "Optical response of $\mathrm{WO}_{3}$ nanostructured thin films sputtered on different transparent substrates towards hydrogen of low concentration," Sensors and Actuators B: Chemical, 2013, 177: 981-988.

[72] M. Shibuya and M. Miyauchi, "Efficient electrochemical reaction in hexagonal $\mathrm{WO}_{3}$ forests with a hierarchical nanostructure," Chemical Physics Letters, 2009, 473(1-3): 126-130.

[73] E. Lee, J. Lee, J. Noh, W. Kim, T. Lee, S. Maeng, et al., "Pd-Ni hydrogen sponge for highly sensitive nanogap-based hydrogen sensors," International Journal of Hydrogen Energy, 2012, 37(19): 14702-4706.

[74] D. Luna-Moreno, D. Monzón-Hernández, J. Villatoro, and G. Badenes, "Optical fiber hydrogen sensor based on core diameter mismatch and annealed Pd-Au thin films," Sensors and Actuators B: Chemical, 2007, 125(1): 66-71.

[75] H. Shanak, H. Schmitt, J. Nowoczin, and C. Ziebert, "Effect of Pt-catalyst on gasochromic $\mathrm{WO}_{3}$ films: optical, electrical and AFM investigations," Solid State Ionics, 2004, 171(1-2): 99-106.

[76] H. Zheng, J. Z. Ou, M. S. Strano, R. B. Kaner, A. Mitchell, and K. Kalantar-zadeh, "Nanostructured tungsten oxide-properties, synthesis, and applications," Advanced Functional Material, 2011, 21(12): 2175-2196.

[77] Y. Baek and K. Yong, "Controlled growth and characterization of tungsten oxide nanowires using thermal evaporation of $\mathrm{WO}_{3}$ powder," The Journal of Physical Chemistry C, 2007, 111(3): 1213-1218. 